WALDEN

UNIVERSITY

A higher degree. A higher purpose.

Walden University ScholarWorks

2019

\title{
Parents' and Health Professionals' Perceptions of Asthma Medication Noncompliance Among Puerto Rican Children
}

Luz E. Nieves

Walden University

Follow this and additional works at: https://scholarworks.waldenu.edu/dissertations

Part of the Epidemiology Commons, and the Public Health Education and Promotion Commons

This Dissertation is brought to you for free and open access by the Walden Dissertations and Doctoral Studies Collection at ScholarWorks. It has been accepted for inclusion in Walden Dissertations and Doctoral Studies by an authorized administrator of ScholarWorks. For more information, please contact ScholarWorks@waldenu.edu. 


\title{
Walden University
}

\author{
College of Health Sciences
}

This is to certify that the doctoral dissertation by

\author{
Luz E. Nieves
}

has been found to be complete and satisfactory in all respects, and that any and all revisions required by the review committee have been made.

\section{Review Committee \\ Dr. Michael Schwab, Committee Chairperson, Public Health Faculty \\ Dr. Katie Callahan, Committee Member, Public Health Faculty \\ Dr. James Goes, University Reviewer, Public Health Faculty}

\section{Chief Academic Officer}

Eric Riedel, Ph.D.

Walden University

2019 


\begin{abstract}
Parents' and Health Professionals' Perceptions of Asthma Medication Noncompliance Among Puerto Rican Children

by

Luz E. Nieves
\end{abstract}

MPH, University of Puerto Rico, 1992

BSN, University of Puerto Rico, 1986

\author{
Dissertation Submitted in Partial Fulfillment \\ of the Requirements for the Degree of \\ Doctor of Philosophy \\ Public Health
}

Walden University

February 2019 


\begin{abstract}
Children of Hispanic origin have the highest prevalence of asthma of all ethnic groups in the United States, especially Puerto Rican children, who have a prevalence of $12.9 \%$. Treatment nonadherence has been identified as one contributing factor. The purpose of this qualitative study was to explore the reasons for nonadherence to the asthma treatment regimen among Puerto Rican children. Parents and health care providers of asthmatic children were interviewed regarding their beliefs about asthma as a disease, its effect on the child's life, and their experience with asthma treatment. Two models served as the theoretical framework: the health belief model and the Institute of Medicine model framework for asthma disparities. Interview data were collected from 8 parents using a questionnaire, and a focus group was conducted with 3 health care professionals. Data were manually coded to identify emerging themes. Even though parents reported fear of asthma medications and medication side effects, none of the parents stopped the asthma treatment. Results also indicated that lack of education about asthma, asthma treatment, and asthma action plan was evident in $75 \%$ of the parents. None of the parents who migrated to the United States from Puerto Rico received education about asthma while living in Puerto Rico. Health care professionals reported that although parents are familiar with asthma, they do not understand that it is a chronic disease that requires daily treatment. Findings may be used to create an asthma education plan tailored to the needs of the Hispanic population.
\end{abstract}


Parents' and Health Professionals' Perceptions of Asthma Medication Noncompliance Among Puerto Rican Children

$$
\text { by }
$$

Luz E. Nieves

MPH, University of Puerto Rico, 1992

BSN, University of Puerto Rico, 1986

\author{
Dissertation Submitted in Partial Fulfillment \\ of the Requirements for the Degree of \\ Doctor of Philosophy \\ Public Health
}

Walden University

February 2019 


\section{Dedication}

I would like to dedicate my dissertation to my daughter, Valeria, an asthma patient from a very young age. I have seen you battling asthma for many years, but this condition was never an obstacle to turn yourself into the great human being you are. You have gone above and beyond all expectations and have shown me a lesson for life. To my husband, Ruben Hernandez, for his unconditional support through this lengthy process. To my dear professor, Dr. Jose Cobos, who taught me the importance of public health and how lives can be transformed by intense work and perseverance. To my mother, Josefina Velez, who passed away while I was writing this dissertation. Mom, thanks for your unconditional love and for never give up on us. 


\section{Acknowledgments}

I want to first give thanks to God Almighty for His love and mercy for my family and me during all times of our life. I have seen His hand guiding and protecting us, and we never feel alone.

Thank you, to Dr. Michael Schwab, for being the chair of this dissertation and for your extraordinary guidance during this long journey with professionalism as you changed my life forever. Thank you, Dr. Maria Rivera, for taking your precious time to read this dissertation and for your valuable feedback, support, and guidance.

Thank you to Dr. Katie Callahan-Myrick for being my committee second member and for your thorough evaluation of this dissertation. Your content evaluation was vital to the completion of this study.

Thank you to my university research reviewer, Dr. Jim Goes, for the evaluation of this document and for recommendations, support, and guidance during the realization of this study.

I want to acknowledge two colleagues who became my sisters after our first residency, Dr. Idania Rodriguez Ayuso and Dr. Jessica Irizarry, for their motivation and for always being on the look for me.

To my husband, Ruben Hernandez, for his support and for understanding this journey. 


\section{Table of Contents}

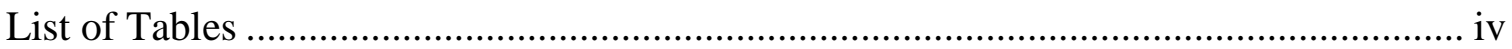

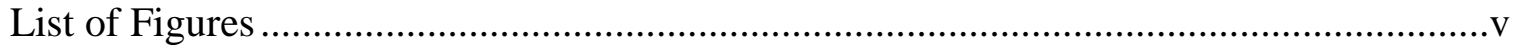

Chapter 1: Introduction to the Study ....................................................................

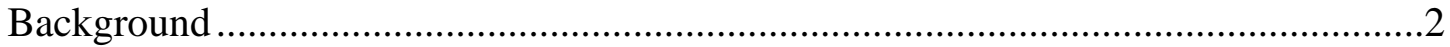

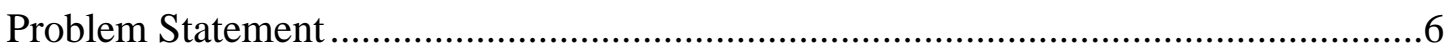

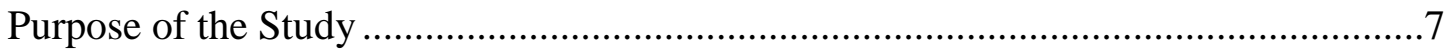

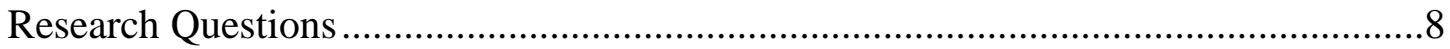

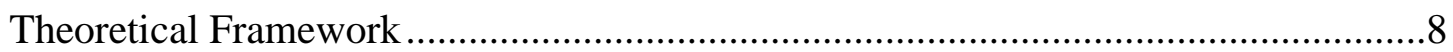

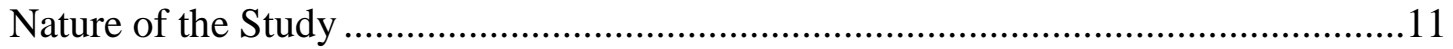

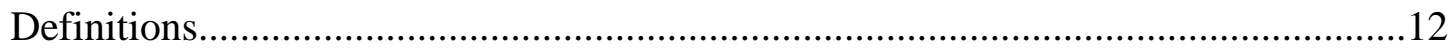

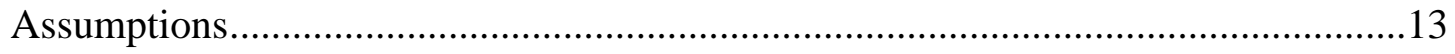

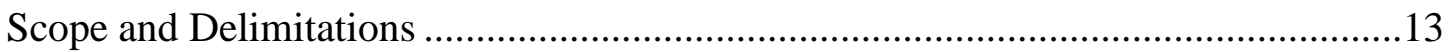

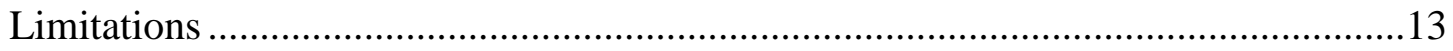

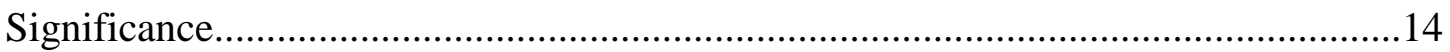

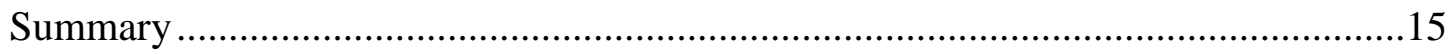

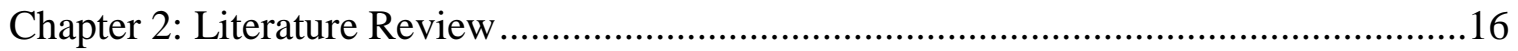

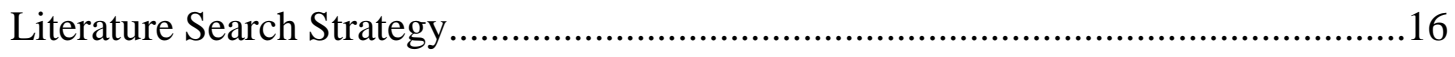

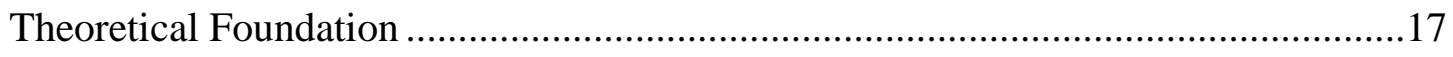

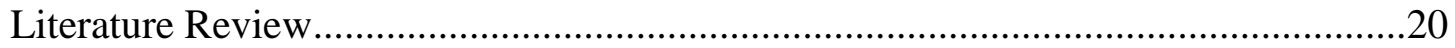

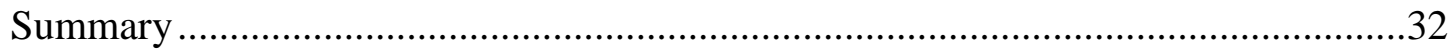

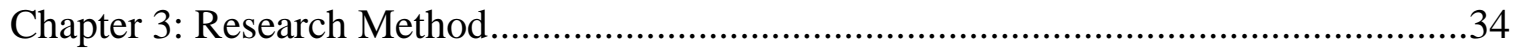




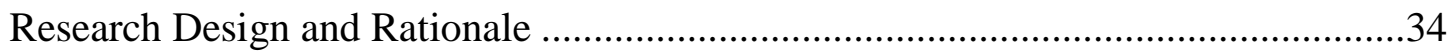

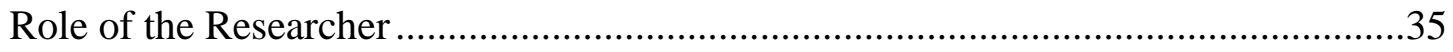

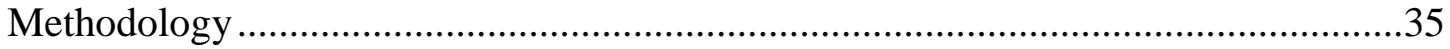

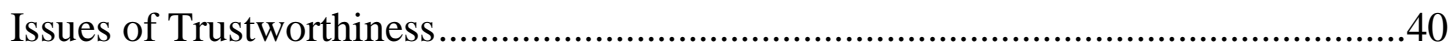

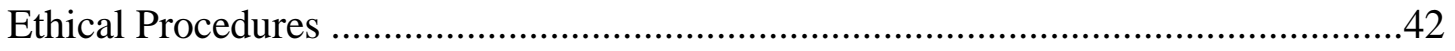

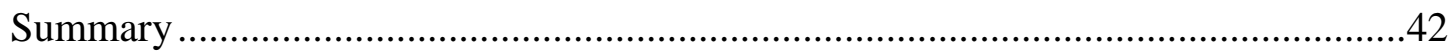

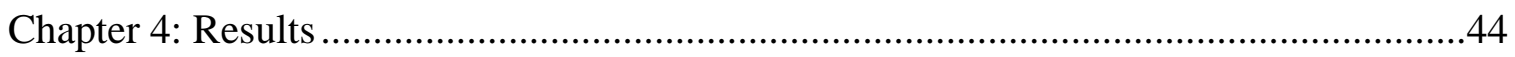

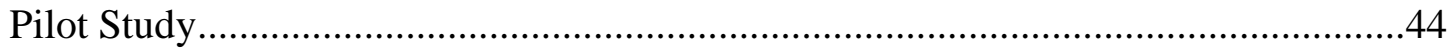

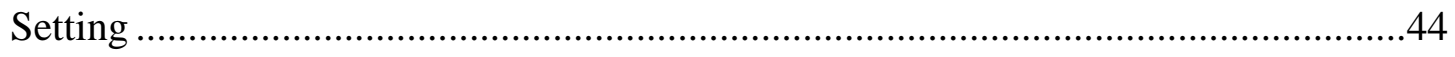

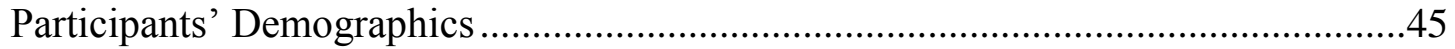

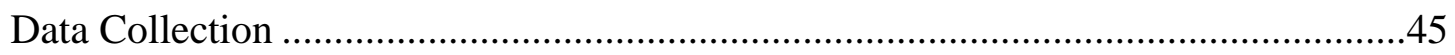

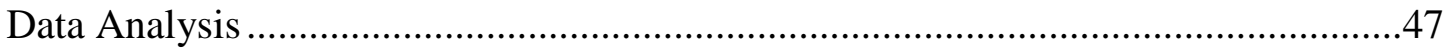

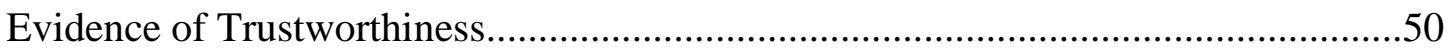

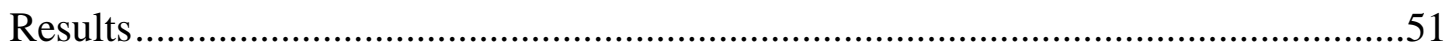

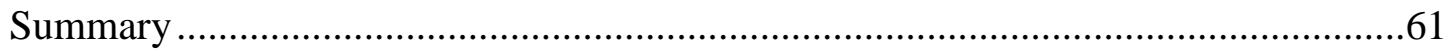

Chapter 5: Discussion, Conclusions, and Recommendations ....................................63

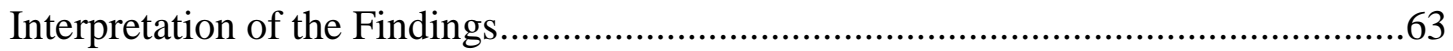

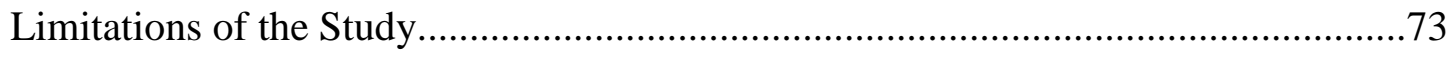

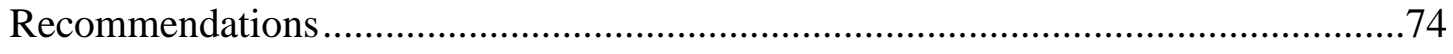

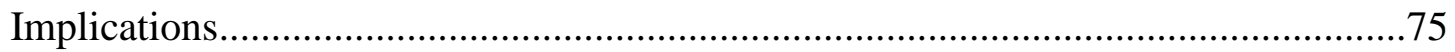

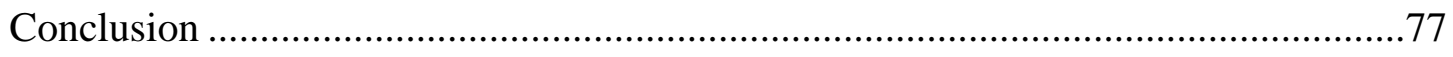

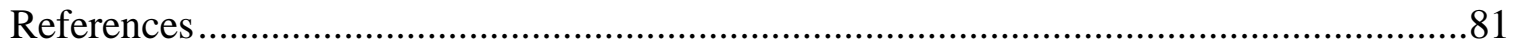


Appendix A: Interview Questionnaire (English) .................................................93

Appendix B: Interview Questionnaire (Spanish) .................................................95

Appendix C: Study Promotion and Invitation to Participate (English) ..........................97

Appendix D: Study Promotion and Invitation to Participate (Spanish)..........................98

Appendix E: Parent/Caregivers' Invitation Letter (English) .....................................99

Appendix F: Parent/Caregivers' Invitation Letter (Spanish) .......................................100

Appendix G: Focus Group Questions ........................................................... 101

Appendix H: Permission for the Utilization of Dr. Glorisa Canino's Study Model........102

Appendix I: Focus Group Invitation Letter ....................................................... 103 


\section{List of Tables}

Table 1. Health Belief Model Application to Parental Beliefs about Asthma................. 19

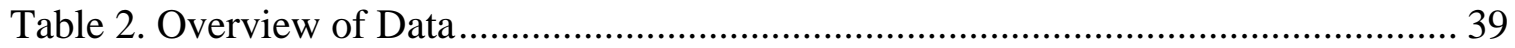

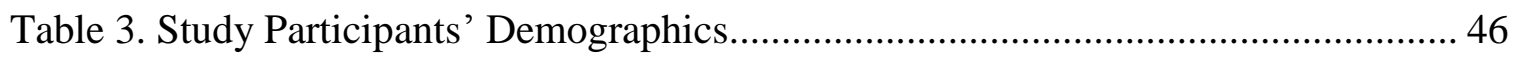

Table 4. Asthma Medication used by the Participants' Children ................................... 46

Table 5. Research Questions and Emergent Codes .................................................. 48

Table 6. Relationship Between Asthma Diagnosis and Familial Occurrence ................. 54

Table 7. Types of Herbal Medicine used by Parents of Puerto Rican Children in

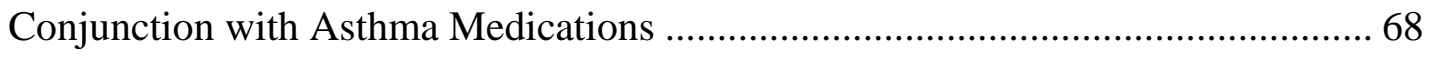




\section{List of Figures}

Figure 1. Multilevel asthma disparities model.....................................................10

Figure 2. Modification of the IOM model of the influence of race, ethnicity, culture, and beliefs/perceptions about asthma medication and provider-patient interaction and

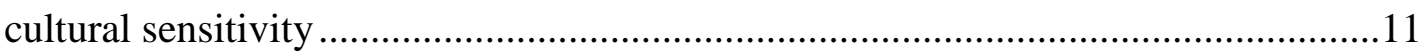


Chapter 1: Introduction to the Study

Over 339 million people worldwide have asthma (National Institute of Health [NIH], 2013; Global Initiative for Asthma [GINA], 2018), including nearly 8.3 million children in the United States, representing $9.3 \%$ of all children nationwide (Centers for Disease Control and Prevention [CDC], 2017). The burden of respiratory diseases affects individuals and their families, schools, workplaces, neighborhoods, cities, and states (United States Department of Health and Human Services [USDHHS], 2013). In 2015, more than 397,000 deaths that were attributed to asthma occurred in the developing world (Ayele \& Getachew, 2017). Asthma morbidity is over represented by ethnic minority urban children (CDC, 2017). In particular, the disease is more prevalent in children from African American and Puerto Rican backgrounds than non-Latino White children, and these differences persist after controlling for socioeconomic status (CDC, 2017). Puerto Rico has a mixed population of African, European, and Native American ancestry (Martinez-Cruzado, Toro-Labrador, \& Viera-Vera, 2005). The prevalence of asthma among children up to 17 years of age by race and ethnicity in the United States was $6.7 \%$ among Hispanics, 5.7\% among Mexicans, 15.1\% among non-Hispanic Blacks, 7.1\% among non-Hispanic Whites, and 12.9\% among Puerto Ricans (CDC, 2017). The prevalence and morbidity rates for asthma are more pronounced in the children of Puerto Rico and non-Hispanic Blacks (CDC, 2017).

These differences highlight a disparity between Puerto Rican children and other children in the United States. There was a need to evaluate the factors that might explain this variance, especially concerning noncompliance with recommended medication, 
which was a significant contributing factor to the prevalence of asthma within Puerto Rican children. I examined parents' beliefs about the disease, its impact on the life of their child, and their experience with asthma treatment prescribed for their children, including low adherence to corticosteroid inhalers. Findings from this study may be used in the planning and development of an asthma education program for the Puerto Rican community that could increase awareness of asthma and the importance of treatment in this population.

This chapter includes a description of asthma and its effect on the Latino community. The background includes a description of asthma and implications of asthma disparities in minority populations. I also address the gap in the literature, the theoretical framework, the nature of the study, and definitions, assumptions, delimitations, and limitations of the study. The significance of the study and a summary are presented at the end of the chapter.

\section{Background}

Asthma is a chronic disease that affects the lungs and airways and can cause episodes of wheezing, cough, chest tightness, and coughing, especially during the night (CDC, 2018). An asthma attack is characterized by difficulty breathing and a reduction of the amount of oxygen that is delivered to the lungs (CDC, 2018). The excess of mucus that accumulates in the bronchial tree during an asthma episode also affects a patient's oxygenation levels by compromising the carbon dioxide and oxygen gas interchange. An asthma exacerbation episode can place the life of a patient in danger if no treatment is received to control the crisis (GINA, 2018). If asthma is left untreated, the patient can go 
into an acute respiratory failure provoked by an exacerbation of an asthma attack (Molfino, Nannini, Martelli, \& Slutsky, 1991). Asthma is a serious and increasing global health problem (Ayele \& Getachew, 2017). The management of asthma includes the utilization of oral or inhaled corticosteroids, bronchodilators, and leukotriene inhibitors (American Academy of Allergy, Asthma, and Immunology [AAAAI], 2013). The purpose of the asthma treatment is to help a patient live a normal life while decreasing and controlling asthma exacerbations (AAAAI, 2013). The adherence to asthma medication is low and is considered one of the causes of asthma morbidity (Pelaez et al., 2015). Noncompliance with a treatment program is common, and rates compliance varies from $20 \%$ to $80 \%$ (Gaude, Hattiholi, \& Chaudhury, 2014). This could be related to patients' lack of understanding of their condition (Gaude et al., 2014). Racial and ethnic disparities have been associated with asthma morbidity and mortality (CDC, 2018). This health disparity is also seen in children of Hispanic origin, and the reason for this difference is unknown (Canino et al, 2009).

The prevalence of asthma is disproportionately elevated in Puerto Rican children, and numerous investigators have tried to explain this phenomenon through the study of different aspects of the disease and the cultural background of caregivers. Multiple biological, social, and environmental risk factors contribute to childhood asthma (Canino et al., 2006). Biological factors include parents and grandparents with asthma, which makes children 4 times more likely to have asthma compared to other children (Valerio, Andreski, Schoeni, \& McGonagle, 2010). Social factors include low socioeconomic status, which tends to increase exposure to psychosocial stress, including violence 
(Kopel, Phitapanatakul, \& Gaffin, 2014). One important environmental factor is environmental pollution, which disproportionately affects Latinos and African Americans because they tend to live in areas that exceed federal standards for toxic pollutants (Wernette \& Nieves, 1992). Even though it is not clear that air pollutants cause asthma, the levels of air pollutants correlate with the prevalence of respiratory illness (Choudhury, Gordian, \& Morris, 1997).

Because environmental factors are complicated to control, medication has become a vital lifeline for most children with asthma, and among Latino children underuse of controller medication (corticosteroids) is a significant problem (McQuaid et al., 2009). This problem is seen when controller medication prescriptions is dispense. According to Halterman, Aligne, Auinger, McBride, and Szilagyi (2000), less than a fourth of controller medication prescriptions for Latino children with moderate to severe asthma were filled in the late 1990s. The rate of controller medication use was lower than for non-Latino White caregivers (i.e., the child's parent, grandparent, or another primary caregiver; Halterman et al., 2000).

One reason for patients' low compliance with their medication regimen appears to be the frequent use of herbal remedies. In their study of the belief systems of Latino caregivers living in Puerto Rico and the Dominican Republic, Koinis-Mitchell et al. (2008) found that beliefs about causes and symptoms were similar between both groups, but Latinos of Dominican descent endorsed a range of home and botanical remedies believed to be useful for treating asthma. The use of these remedies was rare among Puerto Ricans (Koinis-Mitchell et al., 2008). Despite this finding, it still possible that the 
use of herbs in this population may delay the use of asthma medication as an initial response to an asthma attack and exacerbate the progress of the disease (Canino et al., 2006). Most Latinos did not tell their medical providers about the use of folk remedies, compromising effective treatments (Pachter, Cloutier, \& Bernstein, 1995).

Another reason for asthma medication noncompliance is the fear of the side effects of inhaled corticosteroids. This conduct is typical in many types of medications and especially in pediatric medicines because parents are concerned about their children's health. As Boulet (1998) explained it, "misunderstanding of the role of asthma medication and fear of untoward side effects may reduce compliance to therapy, potentially resulting in poor asthma control and increased risk of severe asthma events" (p. 587). Boulet also explained that parents might fear weight gain, change in corporal image, and loss of medication potency over time.

The family plays a significant role in the health of minority children (Canino et al., 2006), and family-based factors are essential in medication adherence among Puerto Rican children. McQuaid et al. (2012) found that Puerto Rican parents were concerned about their children's inhaled corticosteroid use, while the parents of other Latino children were not. Conn, Halterman, Lynch, and Cabana (2007) suggested that a relationship exists between parental beliefs about asthma medication and medication adherence, but it is not clear how a parent's positive or negative feelings about medications influence medication adherence. I attempted to fill this gap by exploring the use of recommended asthma medications, specifically corticosteroids and bronchodilators, among Puerto Rican children living in the United States. 


\section{Problem Statement}

I explored Puerto Rican parents' perceptions of asthma, its causes, and medication compliance, and health care professionals' perceptions of the reasons for parents' low compliance with asthma treatment (see Mowrer, Tapp, Ludden, \& Kuhn, 2014). Asthma is serious disease and one of the most common chronic conditions affecting both children and adults (CDC, 2017). Asthma can cause wheezing, difficulty breathing, coughing, and more severe consequences like permanent lung damage (CDC, 2017). The prevalence of asthma among children 0 to 17 years of age by race and ethnicity in the United States was 6.7\% among Hispanics, 5.7\% among Mexicans, 15.1\% among non-Hispanic Blacks, 7.1\% among non-Hispanic Whites, and 12.9\% among Puerto Ricans (CDC, 2017). The prevalence and morbidity rates for asthma are pronounced in the children of Puerto Rico and non-Hispanic Blacks (CDC, 2017). The lifetime prevalence of asthma for children from Puerto Rico living in the United States is the highest of any ethnic group in the United States (CDC, 2017).

There appear to be many factors contributing to asthma, including biological factors (Valerio et al., 2010), environmental pollution (Wernette \& Nieves, 1992), socioeconomic factors (McQuaid et al., 2012), strong emotions (Canino et al., 2009), and exposure to cold air, humidity, pet dander, and exercise (Lehrer, Isenberg, \& Hochron, 1993). The primary treatments for asthmatic children are inhaled corticosteroids and bronchodilators (AAAAI, 2013). The use of corticosteroids is low among Puerto Rican children compared with the general population (Bartolomei-Díaz, Amill-Rosario, Claudio, \& Hernández, 2011). Because this may be a significant contributing factor to the 
high prevalence of asthma among Puerto Rican children living in the United States, it was necessary to explore the beliefs behind it. At the time of the study, the reasons why corticosteroids do not play a significant role in asthma treatment for Puerto Rican children living in the United States were not well understood. Koinis-Mitchell et al., 2008 , in the study of the beliefs of Latino caregivers of children with asthma, reported that beliefs about asthma have not been intensely studied for the Puerto Rican population, and a scientific investigation is needed. As McQuaid et al (2009) wrote, "the underuse of controller medication may be an important problem for Latino children with asthma" (p. 2).

\section{Purpose of the Study}

My purpose with this qualitative study was to explore why the use of asthma medications is so low among children of Puerto Rican origin living in the United States. I explored parents' sociocultural circumstances and beliefs as they relate to the disease and compliance with doctors' recommendations for treatment. There was a gap in the literature regarding the reasons for lack of compliance from health care providers' and parents' perspectives. Positive social change implications included recognition of parents' beliefs about the disease in the planning and design of an asthma education program for the Puerto Rican community. An education program may help to increase awareness of asthma among Puerto Ricans and may help parents understand the importance of medication adherence in the health of their children. Findings may also be used by medical providers to optimize their education strategies for patients with asthma. Providers who are cognizant of and sensitive to parents' beliefs and cultural norms may 
be more likely to reconcile differences between these beliefs and standard medical practices, and thereby obtain cooperation through family management strategies (Flores, 2000). Asthma management interventions tailored to the needs of a specific community can be an essential tool that clinicians and policymakers can use to reduce asthma morbidity in children (Canino et al., 2007).

\section{Research Questions}

1. What are the perceptions of Puerto Rican parents about asthma and its causes?

2. What are the perceptions of Puerto Rican parents about the asthma treatment recommended for their children?

3. What are the perceptions of health care professionals about the reasons for low asthma treatment medication compliance?

\section{Theoretical Framework}

Two models served as the theoretical framework for the study: the health belief model (HBM) and the Institute of Medicine (IOM) model framework for asthma disparities. The HBM was developed in the 1950s by a group of social psychologists from the U.S. Public Health Service to explain people's lack of participation in health promotion and disease prevention programs (Glanz, Rimer, \& Vismanath, 2008). Six perceptions compose the model: perceived seriousness, perceived susceptibility, perceived benefits, perceived barriers, cues to action, and self-efficacy. Perceived seriousness refers to an individual's beliefs about the severity of the disease based on medical information or knowledge. Perceived susceptibility suggests that the greater the perception of risk, the greater the likelihood of engaging in behaviors to decrease risk. 
Perceived benefits refer to the usefulness of new behaviors in decreasing the risk of acquiring a disease. Perceived barriers are the individual's evaluation of obstacles that may impede adoption of a new behavior. Cues to action are exposures to factors that prompt action, such as a health-related television commercial or a doctor's reminder to get a health revision. Self-efficacy is a person's confidence in his or her ability to act (Glanz et al., 2008). The parents' interview questionnaire was based on the HBM perceptions. HBM has been widely used to explain patient behavior in relation to chronic conditions including asthma.

The IOM's model framework for asthma disparities, shown in Figure 1, focuses primarily on (a) individual/family context as it relates to race, ethnicity, and modifiable factors such as beliefs, health, literacy, and illness management; and (b) provider clinician factors with particular reference to provider/patient interactions as they relate to quality of care and medication compliance. Operation of the health system, with its focus on cultural sensitivity, is also included in the final model. According to Canino et al. (2009), "understanding ethnic and or cultural disparities in asthma morbidity and prevalence is a complicated process" (p. 1). The original IOM model suggests that there is no single risk factor emerging as the primary cause of the health disparity for asthma among children of Puerto Rican descent. Instead, multiple factors appear to be relevant: (a) social and environmental factors, which include poverty and pollution; (b) individual family factors, which include genetics and other biological factors; and (c) individually modifiable factors such as beliefs, health literacy, and illness management. Other areas listed in the IOM model are the health care system and how it interacts with associated 
factors (such as health policies, insurance status, and reimbursement levels) and provider/clinician factors (such as clinician training, prescription practices, diagnosis severity, stereotyping, and provider/patient interaction).

\section{FRAMEWORK OF ASTHMA DISPARITIES}

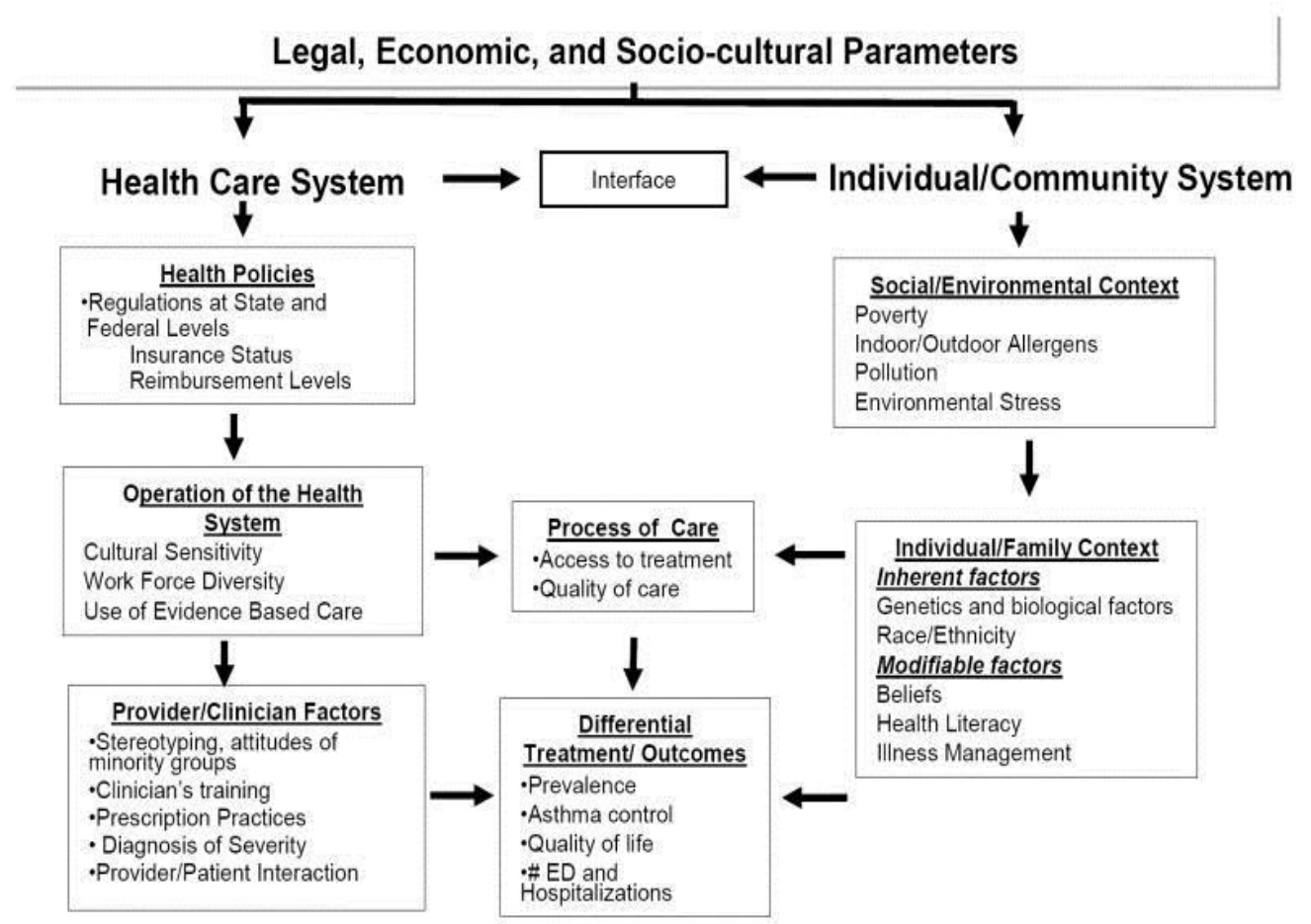

Figure 1. Multilevel asthma disparities model. Adapted from G. Canino (2009) Copyright 2009. Used with permission. (See Appendix H).

Figure 2 presents the modification of the multilevel asthma disparities model, focusing on the inherent, modifiable and provider/clinician factor of the IOM model. 
Race, Ethnicity, Culture

Parents Beliefs/Perceptions about Asthma and Medications

Healthcare Providers Beliefs about Asthma in Hispanic Children

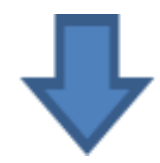

Provider-Patient Interaction

Cultural Sensitivity

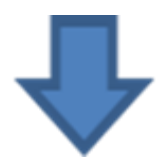

Adherence

Figure 2. The influence of race, ethnicity, culture, and beliefs/perceptions about asthma medication and provider-patient interaction and cultural sensitivity (modification of the IOM).

Knowing parents' perceptions and beliefs about asthma may help health care providers develop an educational program suitable to the Hispanic population. Better parent education may have a direct effect on adherence to the medication regimen and better health outcomes for the children.

\section{Nature of the Study}

I conducted a qualitative study of parents' and health care practitioners' attitudes and beliefs about asthma and its treatment. The value of qualitative methodology lies in the ability to answer research questions that are not answerable by experimental methods 
(Green \& Britten, 1998). A qualitative approach to asthma and asthma medication adherence was a new way to view this problem. The parents' interview questionnaire was based on the HBM perceptions. The questionnaire was administered in English and Spanish to accommodate the participants. Another strategy for data collection in this study was a focus group. This type of data collection offers the opportunity to collect indepth data quickly and efficiently (Joseph, Griffin, \& Sullivan, 2000). The focus group data were collected from health care providers.

\section{Definitions}

Asthma: Chronic lung disease that inflames and narrows the airways, characterized by episodes of chest tightness, coughing, and wheezing (USDHHS, 2014).

Asthma action plan: Written medical instructions developed by the physician to help control patient asthma. These instructions include how to handle daily treatment and how to handle and asthma attack (CDC, 2012).

Corticosteroids: Medication used to prevent flare-ups of asthma by decreasing inflammation of the airways and lungs (AAAAI, 2018).

Health disparities: The difference in treatment or access not justified by the differences in health status or preferences of the groups (McGuire, Alegria, Cook, Well \& Zaslavsky, 2006).

Hispanic/Latino: Person of Cuban, Mexican, Puerto Rican, South or Central American, or other Spanish culture or origin (United States Census Bureau, 2018). Medication adherence: The degree to which use of medication by the patient corresponds with the prescribed regimen (World Health Organization, 2018). 
Puerto Rican descendant: Person born from parents born on the island of Puerto Rico.

\begin{abstract}
Assumptions
In this study, I used data from Puerto Rican families with children who moved to the United States. The assumptions about this population were as follows: (a) the data collected from the parents in the United States were similar to the data of the parents living in Puerto Rico, (b) the participants' place of residence did not affect the results of the study, and (c) caregivers' place of residence did not change their beliefs about asthma treatment and adherence to medication regimen.
\end{abstract}

\title{
Scope and Delimitations
}

The study population was parents of children diagnosed with asthma who were born in Puerto Rico and living in Southeast, United States at the time of the study. The ages of the children were 1 to 17 years. This study did not include children of other Hispanic origin such as the Dominican Republic or Mexico. Children who were born in Puerto Rico to parents of a different nationality were not included.

\section{Limitations}

This study had several limitations. The inclusion criteria were parents with children between the ages of 1 and 17 years. This age group may not have been sufficient to answer the research questions. The participant recruitment sources included a pediatric office and a religious organization. This geographical area is well known for the largest concentration of Puerto Ricans living in the state of Florida. Due to the small sample size, the study results cannot be generalized to the broader Puerto Rican population. 


\section{Significance}

Asthma affects people of every race, sex, and age. However, significant disparities in asthma morbidity and mortality exist for low-income and minority populations (Office of Disease Prevention and Health Promotion [ODPHP], (2018). Children are included in the populations with higher rates of asthma (ODPHP, 2018). The effects of this problem in asthmatic children may include increased health service utilization, economic implications for the family, school absenteeism, decreased family activities, and plans for the future (Wood, Hidalgo, Prihoda, \& Kromer 1993).

Puerto Rican children in the United States and Puerto Rico have the highest lifetime prevalence of asthma of any ethnic group. The reason for noncompliance with the medical regimen is still unknown. The results of this study may help health care providers develop education programs and treatment strategies targeting this specific population. The study of cultural beliefs among Puerto Rican parents may contribute to a better understanding of how parents' beliefs about asthma affect their behavior and adherence to their children's medication regimen. Positive social implications also include the recognition of the caregiver's beliefs about the disease in the planning and design of an asthma education program for the Puerto Rican community. Findings may also be used to increase awareness of asthma in the Puerto Rican population and to help health care providers optimize education strategies used for pediatric patients with asthma. 


\section{Summary}

The high prevalence of asthma among Puerto Rican children is an example of a health disparity affecting one specific ethnic group. There are several possible reasons for this difference, including low compliance with medication. I explored parents' and health care providers' beliefs about asthma and noncompliance with asthma medication. At the time of the study, researchers had not addressed this problem using qualitative methodology. The HBM and the IOM model of asthma treatment were used to develop the interview questionnaire and focus group questions. Findings from the study may provide a better understanding of the reasons for high prevalence of asthma among Puerto Rican children, which may be used to improve education strategies for children with asthma. Chapter 2 contains a review of the literature on the nature, causes, and treatment of asthma among Puerto Rican children and the theoretical frameworks of this study. 
Chapter 2: Literature Review

Compliance with pediatric asthma medication regimens differs by ethnicity and race (Burgess, Sly, \& Devadason, 2011). When subgroups are disaggregated, Puerto Rican children have the lowest medication compliance rate of all sub-groups (Canino et al., 2006). Current research in medication compliance has demonstrated that adherence to inhaled asthma medication is low in poor children (Canino et al., 2006). Multiple researchers have explored the reasons for poor adherence to corticosteroid therapy in Puerto Rican children, but the underlying causes are still not understood (Bartolomei et al., 2011). I examined parents' beliefs and fears about asthma, asthma medication, medication adherence, and the use of herbal medicine. I also explored health care professionals' perceptions of noncompliance with asthma medications. This chapter includes a literature review supporting this study, including studies from the United States and Puerto Rico. The chapter includes the theoretical framework (HBM, IOM), asthma (definitions, prevalence, and national response), asthma epidemiology (biological, social, and environmental factors), asthma treatment (clinical and herbal), asthma education, and asthma action plan.

\section{Literature Search Strategy}

I used Walden University's library databases. I also used PubMed Researchgate and Google Scholar linked to the Walden University library.

The search key terms included asthma Puerto Rican children, Puerto Rican children, asthma minority, parental beliefs, treatment compliance, fear medications side effects, health disparities, and belief about medications. I used different combinations of 
terms like Hispanic children, Latino children, Puerto Rican children, and health disparities. The primary sources of scientific information for this study were peerreviewed journals and government databases such as the Centers for Disease Control and Prevention, NIH and GINA. The publication dates were 1992 to 2018. I used articles older than 5 years to provide historical content as needed.

\section{Theoretical Foundation}

In 1950, a group of social psychologists from the U.S. Public Health Service developed the HBM. The need to explain the lack of participation of people in health promotion and disease prevention was the reason this model was created (Glanz et al., 2008). The HBM is based on six perceptions. Perceived seriousness refers to an individual's beliefs about the severity of the disease based on medical information or knowledge. Perceived susceptibility suggests that the higher the perception of risk, the higher the likelihood of engaging in behaviors to decrease risk. Perceived benefits refer to the usefulness of a new action in reducing the risk of acquiring a disease. Perceived barriers are obstacles that impede adoption of a new practice. Cues to action are factors that prompt action, such as a health-related television commercial or a doctor's reminder to get a health revision. Self-efficacy is the confidence to act (Glanz et al., 2008).

Since the early 1950s, the HBM has been one of the most widely used conceptual frameworks in health behavior research to explain change and maintenance of health related-behaviors and as a guiding framework for health behavior interventions (Champion \& Skinner, 2008). The HBM has been applied to study patient behavior in multiple medical conditions like diabetes, breast cancer, and chronic obstructive 
pulmonary disease. Brown, Ottney, and Nguyen (2011) incorporated the HBM to determine patients' emphases on pregnancy prevention when examining the discrepancy between pregnancies and the use of contraceptives. McQuaid, Kopel, Klein, and Fritz (2003) used the HBM to demonstrate that health care practitioners should consider developmental issues in the assessment and treatment of children with asthma. McQuaid et al. 2003 found that "tailoring educational materials to the developmental level of the child may be critical in facilitating comprehension" (p. 331).

The theoretical foundation of this study was the HBM. This model was used to explain how parents' beliefs about medications influenced medication regimen adherence. Parents are the gatekeepers of their children's health. Parents' beliefs about medications could affect their children's treatment compliance. Table 1, shown the application of the HBM to the parental beliefs about asthma. 
Table 1

Health Belief Model Application to Parental Beliefs about Asthma

Health belief model Application to parental beliefs about asthma

Perceived susceptibility $\quad$ Fear of having a child with asthma having a history of familiar asthma

Perceived severity

Feeling about how the family is going to be affected by having a child diagnosed with asthma. Economic impact. Loss of work days altered family life and social relations.

Perceived benefits Parents will receive the benefits of fewer asthma attacks in children if they understand the treatment regimen and how important it is to follow the medical recommendations.

Perceived barriers

Financial impact, medication accessibility, affordability of medication, lack of medical insurance or government support. Job interruption, loss of work days due to child illness. Risk of losing their job or income due to unplanned absences. Fear of condition deterioration and need for hospitalization. Fear of child weight gains due to corticosteroid therapy. Fear of medications sides effects and dependence.

Cues to action Media announcements about children with asthma being unable to breathe. News about children dying of asthma attacks.

Self-efficacy Parental education about the acceptable way of delivering medications to their children. 
The HBM is related to the concept that people will seek a change in behavior only if they know they are at risk (Boskey, 2016). The model was used to create the interview questionnaire and focus group questions aimed at exploring the reasons why compliance with asthma treatment is so low in Puerto Rican children. The HBM concepts of perceived severity and perceived barriers were used in this study. To ensure validity, it is essential to measure the full range of factors that may influence the behavior (Champion $\&$ Skinner, 2008). The needs of asthma medication treatment versus the fear of a medication's adverse effects were weighed. The barriers related to the lack of medication adherence were evaluated. Parents' perception of asthma was assessed using the perceived severity concept of the HBM.

\section{Literature Review}

\section{Asthma Definition}

The CDC (2017) defined asthma as a chronic inflammatory disorder of the airways characterized by episodic and reversible airflow obstruction and airway hyper responsiveness. The clinical manifestations of asthma include wheezing, coughing, and shortness of breath (CDC, 2017). These episodes can range in severity from mild to lifethreatening. Symptoms of asthma include wheezing, coughing, chest tightness, and shortness of breath. Daily maintenance treatment can prevent symptoms and attacks and enable individuals who have asthma to lead active lives (USDHHS, 2013). Asthma is one of the most common chronic diseases of childhood affecting more than 8.3 million children (CDC, 2017). There is no cure for asthma, but once it is diagnosed and a treatment plan is in place, the patient can manage his or her condition and improve his or 
her quality of life (AAAAI, 2014a). Asthma can affect anyone. However, specific populations are at higher risk, including children, women, Black and multiracial Americans, Native Americans, and Alaskan Natives (CDC, 2014a). The triggers of an asthma attack include airborne allergens such as pollen, mold, animal dander, dust mite, and cockroach allergens (Canino et al., 2006). Further triggers include airway infections and occupational exposures to toxic chemicals and airborne irritants such as tobacco smoke and automobile exhaust (Canino et al., 2006). Exercise has also been identified as a trigger for asthma (CDC, 2014a). The burden of asthma is characterized by multiple factors including the number of asthma-related hospitalizations, emergency room visits, and deaths (CDC, 2014a).

\section{Asthma Prevalence}

Data from the CDC indicated that asthma poses a severe concern for the population. In 2016, the prevalence of asthma among children 0 to 17 years of age by race and ethnicity in the United States was 6.7\% among Hispanics, 5.7\% among Mexicans, 15.1\% among non-Hispanic Blacks, 7.1\% among non-Hispanic Whites, and 12.9\% among Puerto Ricans (CDC, 2017). A total of 415 asthma deaths were reported in Puerto Rico for the 2010-2015 periods (Bartolomei-Díaz, Hanisch, Ruiz- Serrano, DiazIrizarry, \& Montalvo-Felix, 2017). The asthma mortality rate adjusted by age for 20102015 was 2.18 per 100,000 inhabitants for Puerto Rico and 1.06 per 100,000 inhabitants in the United States (Bartolomei-Díaz et al., 2017).

When the asthma mortality rates of Puerto Rico and the United States are compared, Puerto Rico's rate is 1.12 times higher than that of the United States for the 
same year (Bartolomei-Díaz et al., 2017); (Departamento de Salud, 2018). According to the CDC (2014c), from 2014 to 2015 an estimated 131,763 (15.5\%) children who lived in Puerto Rico had asthma. That meant that 1 of every 7 children who lived in Puerto Rico had asthma. The age groups with the highest prevalence were 5-9 years old (18.0\%) and 10-14 years old (17.8\%; CDC, 2014c).

In 2013, asthma caused 13.8 million missed school days and 14.2 million missed days of work (CDC, 2014d). Of the total missed school days in $2013,56.5 \%$ were attributed to Hispanic children (CDC, 2014d). One in five children went to an emergency department for asthma-related care (CDC, 2014d). Nearly 1 in 2 children with asthma reported missing at least one day of school each year because of asthma (CDC, 2014d). In 2012, the cost of treatment for a child with asthma ranged from $\$ 833$ to $\$ 1,121$ per year, and the total cost of asthma to the United States was \$56 billion (AAAAI, 2014a). There were 3,615 asthma-related deaths in $2015 ; 219$ of those deaths were attributed to children under 18 years of age (AAAAI, 2018).

Numerous studies have addressed asthma and its effects on the minority population. However, most of the studies have been done using quantitative methodology. Bartolemei-Díaz et al. (2011), in their study of asthma mortality in Puerto Rico from 1980 to 2007, found a higher mortality rate than in most other countries, including Austria, Finland, France, Germany, Italy, and Spain. This disparity was especially pronounced among minority children, though the mechanisms accounting for it are poorly understood (Canino et al., 2006). 


\section{National Asthma Response}

Asthma continues to represent a challenge to public health organizations and health care providers and a puzzle for researchers searching for its primary causes (Akinbami, Moorman, Garbe, \& Sondik, 2009). For many years, efforts have been focused on tracking the prevalence of the disease and managing its cost. In 1999, the CDC created the National Asthma Control Plan to help the nation in the reduction of the national burden of asthma. Over the last 12 years, the National Asthma Control Plan has reduced medical expenditures by $\$ 23.1$ billion (due to a shift of medical visits from emergency rooms to medical offices) and implemented better asthma surveillance.

Eight percent of Americans have asthma, more than nine people die from asthma every day, and about 1 in 11 children had asthma in 2010 (CDC, 2014a). However, despite these measures, new investigations done with asthma, and new asthma medications, the asthma burden still exists, and children still suffer from asthma attacks. The increasing prevalence of asthma remains a complex situation (Reed, 2006).

\section{Asthma Epidemiology}

The reasons for the dramatic differences in asthma prevalence between Puerto Rican children and children from other ethnic groups, and between Puerto Rican children and Cuban, Mexican, Puerto Rican, and Dominican children, are still relatively unclear. However, there is evidence that multiple biological, social, and environmental factors are related to treatment. 


\section{Biological Factors}

Puerto Rican children may have a genetic disposition to asthma not present in any other racial or ethnic group (Escarce, Morales, \& Rumbaut, 2006). Genetic asthma research has progressed to the extent that studies on the ADAM 33 gene have been done in the Caucasian population and associations have been documented. This type of genetic association has not been found in the Puerto Rican and Mexican population. The genetic association between asthma and Puerto Ricans is still unclear. Family history and asthma were areas of recent studies. Investigations have focused on parental influence, birth order, genetic predisposition, and maternal asthma (Valerio et al., 2010). According to Valerio et al. (2010), children whose parents and grandparents have asthma are four times more likely to have asthma than children whose parents or grandparents do not have asthma. This finding may encourage practitioners to add parental asthma information to the medical history during the first visit to the physician. Clinicians may use the asthma history of the parents and grandparents as an indicator of asthma in early childhood (Valerio et al., 2010).

\section{Social Factors}

Low socioeconomic status, exposure to psychosocial stress, and violence have been linked to worsened asthma outcomes in children; the variables included in socioeconomic status are household income, caregiver employment, education status, living conditions, and minority living locations (Canino et al., 2006). The reasons for worsened asthma in children who are exposed to psychosocial stress and violence are not clearly understood. However, one theory is that stress affects the inflammatory response 
of the body (Black, 2002). Researchers have found an increase in exhaled nitric oxide in asthmatic subjects after an acutely stressful event (Kopel et al., 2014). The educational status of the caregiver is a high predictor of asthma exacerbations; a lack of understanding of the disease and the asthma treatment plan may put at risk the adherence to the treatment. Asthmatic children that are socially disadvantaged are at higher risk of asthma morbidity (Kopel et al., 2014). The interaction between the socioeconomic status of the caregiver, education, stress, and violence may play a significant role in the children's condition. These factors should be considered in the planning of an asthma control strategy.

Garro (2011) explored the coping mechanisms of Latino families with an asthmatic family member. Partnerships between health care providers, nurses, physicians, and therapists are crucial in making sure the family feels comfortable working with their children's medical team (Garro, 2011). Historically, Latinos with asthma have received less attention than persons of other groups, even though they also experience high rates of this disease (Garro, 2011). Beliefs about medicines predict adherence more strongly than socio-demographic or clinical factors (Horne, Weinman \& Hankins, 1999). The parents' cultural beliefs about asthma represent a gray area that needs more in-depth investigation. Despite the increase in asthma prevalence among Hispanics, community cultural beliefs about asthma may influence treatment behavior (Koinis-Mitchell et al., 2008).

\section{Environmental Factors}

Some of the environmental factors contributing to asthma prevalence and incidence are allergens such as dust, mites, cockroaches, and environmental pollutants 
(USDHHS, 2012). These factors have not been reported to cause asthma, but they can exacerbate asthma through a repetitive irritation of the airway epithelium (Leikauf, 2002). Some chemicals that have been associated with asthma exacerbation are aldehydes (such as acrolein and formaldehyde) and metals (such as nickel and chromium; Leikauf, 2002).

The American Lung Association (2014) pointed out that people with asthma are particularly sensitive to outdoor pollution. The most common air pollutants and asthma triggers are vehicle exhaust, wood smoke, and fumes. These sources of air contamination are beyond parental control. Controlling asthma triggers is an essential aspect of the asthma treatment plan. Achieving and maintaining asthma control also requires caregivers to address environmental factors that worsen symptoms (USDHHS, 2012). The high rate of low-income status among Latinos results in this population being more exposed to indoor and outdoor allergens.

\section{Health Care Factors}

Canino et al. (2006) studied the IOM's conceptual model to explain pediatric asthma disparities. According to the IOM, health disparities are defined as "racial or ethnic differences in the quality of healthcare that are due to access-related factors or clinical needs, preferences, and appropriateness of intervention" (p. 2297). The IOM model has different factors that explain disparities, including the health care system; the provider's beliefs, biases, and stereotyping; and patient needs, beliefs, and expectations (Canino et al., 2006). In this model, the patient seeks medical care based on beliefs and expectations shaped by sociocultural factors (Canino et al., 2006). 
Several studies have addressed pervasive asthma disparities in prevalence, severity, and mortality in minority populations when compared to non-Latino Whites (Canino, McQuaid \& Rand, 2009). Still, the underlying causes of these disparities are not well understood. Canino et al. (2009) recommended a multilevel view of asthma to understand why these disparities are happening. They also recommended several strategies that could be utilized in clinical settings to reduce asthma disparities, including routine assessments of patient beliefs, financial barriers to disease management, and health literacy, and the provision of cultural competence training and communication skills to health care.

\section{Asthma Treatment}

This section contains information related to traditional asthma treatment and other alternative methods utilized to treat asthma. I will analyze clinical asthma studies and parental beliefs about asthma treatment.

Clinical asthma treatment. According to the AAAAI (2014b), the treatment of asthma includes the daily use of controller medications such as inhaled corticosteroids and long-acting beta-agonists. Oral-form medications for asthma include leukotriene modifiers. Quick-relief medicines are known as short-acting beta-agonists. These medications are only used when immediate relief is needed. Oral and intravenous corticosteroids are required to treat acute and severe asthma attacks (AAAAI, 2014b). Researchers have suggested that only $50 \%$ of prescribed preventive asthma medications are taken as directed (Conn et al., 2007). 
Although asthma has no cure, the symptoms and costs can be controlled when people have the appropriate care, education, and guidance to manage their condition (CDC, 2014a). The treatment of asthma is a multidisciplinary team effort that entails the use of multiple health care professionals such as pediatricians, pulmonary medicine specialists, allergy and asthma specialists, respiratory therapists, professional nurses, social workers, pharmacists, asthma educators, and school nurses. The health care providers' involvement plays a vital role during the course of asthma treatment. The multidisciplinary team approach given by health care professionals to the patient and family will play a significant role in the life of the patient and their family. Public health programs and policies that influence asthma management include the National Asthma Control Program (CDC, 2014a), the Global Initiative for Asthma (GINA), and the Department of Health and Human Services (DHHS) asthma control program.

In a cross-sectional survey of parents of children with asthma, Conn et al. (2007) evaluated the importance of controller medications for the parents. Using the Beliefs about Medications Questionnaire, Conn et al. examined the children use of medicines and parents' positive or negative attitudes towards their children's asthma medications. A better understanding of parents' medication beliefs and their impact on adherence may help clinicians to counsel effectively and promote adhesion (Conn et al., 2007).

Boulet (1998) analyzed the role of medications' side effects. by evaluating 603 asthmatic patients' fears of asthma medications' side. The results indicated that a high proportion of asthmatic patients do not understand the importance of asthma medication treatment and fear corticosteroids therapy. To provide appropriate education and 
counseling to the patients, the caregivers need to question the patients regarding their understanding of the role of asthma medications (Boulet, 1998). Being from a lowincome family has also been studied as a factor for poor medication adherence, especially controller medications. Children of low-income families are more likely to use the emergency room (ER) for their asthma care than their higher-income counterparts (Koinis-Mitchell et al., 2010). Even though this behavior results in higher costs for the parents, a lack of medication could also be a reason for non-compliance with treatment. McQuaid et al. (2012) studied medication adherence among Latino and non-Latino White children with asthma. The researchers investigated why the use of corticosteroids is still suboptimal, particularly among minorities. Addressing parental beliefs about medications may benefit families from different cultural backgrounds (McQuaid et al., 2012).

Herbal medicine treatment. In Puerto Rico, folkloric medicine is still widely used and respected. A mix of three races--the Spaniards, the Indians, and the Africans-has brought to the island a natural medical system administered by a health practitioner known as the "curandero" (Torres \& Sawyer, 2005). This type of ethnomedicine is used in the treatment of asthma. As in Chinese, Mexican, and other indigenous medical systems, Puerto Rican ethnomedicine practices attempt to maintain physical and emotional balance and harmony through botanical medication, prayer, and other therapies (Pachter, Cloutier, \& Bernstein, 1995).

Common folk remedies for asthma in children and adults include garlic (mixed into a cough syrup), eucalyptus (as an inhalant), mullein, and oregano (Neff, 2014). The worldwide use of herbal and alternative medicine prevalence varies widely, from $4 \%$ to 
79\% in adults (Ernst \& Posadzki, 2012). In children, this prevalence, although less researched, is also high (Ernst \& Posadzki, 2012). According to the National Center for Complementary and Integrative Health (2007), the prevalence of children using alternative medicine in the United States is $11.8 \%$.

Personal beliefs play a significant role in the type of folk medicine used by the caregiver. During the process of growing up, people can learn the concepts of sickness and health along with religious faith through their family (Neff, 2014). Regardless of each ethnic group's beliefs and remedies for asthma, one common factor is the failure of parents to access a western physician, thus potentially placing the lives of their children at risk (Zayas, Wizniewsky, Cadsow, \& Tumiel-Berhalter, 2011).

Herbal medicines, when used with asthma medications, can either increase or decrease the effect of the drug, resulting in potentially adverse effects on the patient. The practitioner needs to discuss the use of herbal medicine with parents before altering the asthma treatment (Lim, Cranswick, \& South, 2010). Health care professionals should always be aware of the use of herbal medicines and advise their patients accordingly (Ernst \& Posadzki, 2012).

\section{Asthma Education}

Educational programs for asthmatic patients are vital and can improve treatment adherence and self-management (Gaude, Hattiholi, \& Chaudhury, 2014). Patients that adhere to their treatment have a better understanding of the disease, know what options they have to control the symptoms, and can keep the illness exacerbation to a minimum 
(Gaude et al. 2014). Patient education is one of the major methods used to maintain patient medication compliance.

Asthma education is vital at all ages, but when the disease is diagnosed in children, is imperative that the parents are educated regarding the disease (Kelso, 2016). Asthma education involves an explanation of asthma pathophysiology, the use of medications, and the correct use of medication delivery devices such as metered dose inhalers, spacers, nebulizers, and powder inhalers in dry form (Kelso, 2016). The physician needs to educate the parents about the treatment expectations and urge them to notify the doctor if the child does not respond to treatment (Kelso, 2016). Low compliance to the asthma therapy can increased morbidity and mortality; rates of noncompliance to asthma medication have been calculated between $20 \%$ and $80 \%$ (Gaude et al., 2014). One of the reasons for non-compliance is that patients with a chronic disease do not have a clear understanding of the disease. The lack of education could cause parents to underuse or not use the asthma medications, increasing the financial burden caused by asthma (Gaude et al., 2014).

\section{Asthma Action Plan}

Asthma action plans are medical instructions developed by physicians to help control their patients' asthma; these instructions include how to handle daily treatment and how to handle an asthma attack (CDC, 2012). Each plan is individualized to the medical needs of each patient. All patients should be provided with an asthma action plan according to their health literacy and the severity of their disease (GINA, 2018). The asthma action plan should include information about patient asthma medications, under 
what circumstances the medication should be increased, and when to call the doctor or ask for immediate medical attention (GINA, 2018).

Gillette et al. (2013) conducted a cross sectional study with 35 pediatric health care providers and caregivers. In their study, 260 asthmatic children from ages 8 to 16 were included. Patients' visits with their doctor were audiotaped, transcribed, and coded. The data were examined for discussions about the asthma treatment plan. The results of the study reflected that only $21 \%$ of the children and caregivers were provided with an asthma action plan. The patients that were covered under a Medicaid plan were more likely to have received an asthma action plan from their health care provider. It is important to discuss an asthma action plan with every asthmatic patient and their caregiver, especially with patients with persistent asthma. The asthma action plan should be revised regularly (Gillette et al. 2013).

The utilization of an asthma action plan was found to have benefits for the patients, caregivers, and physicians, including fewer asthma attacks, better sleep, fewer missed days at school, and better control of asthma symptoms (Gillette et al., 2013). Professional organizations like the U.S. Pharmacopeia and the National Heart, Lung, and Blood Institute advocate for asthma education and encourage health care providers to teach children and caregivers about their asthma medications and self-management (Gillette et al., 2013).

\section{Summary}

Through the literature review, I explored the definition of asthma, asthma medication compliance, asthma epidemiology, cultural beliefs about medications, asthma 
action plans, and parental knowledge of the disease. The HBM helped me to understand how comprehension of the psychological aspects of a disease may play a significant role in treatment compliance. Other issues such as fear of medications' side effects and parental coping mechanisms for their children's condition are areas that need further investigation. Cultural beliefs about the nature of asthma may influence treatment behavior (Koinis-Mitchell et al., 2008). Asthma is still a burden for Hispanic the population. The growth of the U.S. population from the year 2000 to 2010 was 28 million. Of this amount, more than $50 \%$ (15.4 million) of the increase was due to the immigration of Hispanics alone (Kochhar, Gaviria \& Ballas-Traynor, 2012). Asthma action plans play a significant role in the management of asthma in children and adults. The use of the plan is encouraged by health care associations like the U.S. Pharmacopeia, the National Heart, Lung, and Blood Institute (Gillette et al., 2013), GINA (2018), and the Centers for Disease Control and Prevention (2018).

In this chapter, I presented evidence of the need for asthma programs based on the cultural beliefs of the community. I designed the current study to provide data that could be used to create an asthma program suitable for Puerto Rican families in the United States. This may represent a step toward closing the gap of health care disparities in the Latino community. Chapter 3 contains a description the methodology used in the study. 
Chapter 3: Research Method

The purpose of this study was to explore the beliefs and perceptions of health care professionals and Puerto Rican parents regarding their children's asthma treatment. Belief about medicines predicts adherence more strongly than sociodemographic or clinical factors (Horne \& Weinman, 1999). This chapter includes the research design and rationale, role of the researcher, methodology, instrumentation, data collection instruments, recruitment, participation selection, collection and analysis of data, trustworthiness, and ethical procedures.

\section{Research Design and Rationale}

I chose the qualitative method for this study. In qualitative research, there are always two key players: the participant who contributes the information and the researcher who guides the inquiry (Ulin, Robinson, \& Tolley, 2005). Investigators gather what they see, hear, and read about people, places, and events with the purpose of learning about the social world and generating an understanding that can be used by that social world (Rossman \& Rallis, 2003). The data for this study were collected using an interview questionnaire and focus group questions that addressed parents' perceptions and beliefs about asthma in children and health care professionals' beliefs about the reasons for noncompliance with medications. The research questions for this study were the following:

1. What are the perceptions of Puerto Rican parents about asthma and its causes?

2. What are the perceptions of Puerto Rican parents about the asthma treatment recommended to their children? 
3. What are perceptions of health professionals about the reasons for low asthma treatment medication compliance?

\section{Role of the Researcher}

My role was to collect questionnaire data from the parents and record the responses on an audiotape. I also conducted a focus group session with the health care professionals. I did not have any personal or professional relationship with the participants. The data were not collected in my workplace. A hypoallergenic pillow cover was given to every parent who participated in the study as a gesture of appreciation for participation. This gift was provided after the parent completed the questionnaire interview.

\section{Methodology}

A flyer inviting participants (see Appendix C and D) was placed in a pediatric medical office and a Hispanic church. This area is known for a high population of Hispanics of Puerto Rican origin. I did not have any relationship with the participants, office personnel, or medical staff other than administering the interview questionnaire and conducting the focus group. No ethical issues or conflicts of interest arose during the study.

To be included in the study, the parents met the following criteria: (a) born in Puerto Rico; (b) have a child between 1 and 17 years of age; (c) the child has been diagnosed with moderate to severe asthma during the last 12 months; and (d) the child has been prescribed corticosteroids and bronchodilators, inhaled or oral. Interested parents contacted me through the university e-mail address included in the flyer. The 
parents were reached by phone and formally invited to participate. This invitation was extended to Hispanic parents of Puerto Rican origin only.

Initially, the total number of participants was 25 . However, saturation was met with eight subjects. According to Mason (2010), qualitative samples must be large enough to ensure that most or all the perceptions that might be important are uncovered; if the sample is too large, the data will become repetitive and eventually superfluous. According to Charmaz (2006), the aims of the study are the drivers of the project design and the sample size. Because the study aims were perceptions and beliefs about asthma medications from parents and health care professionals of children with asthma, I expected to achieve saturation with the estimated number of subjects. Charmaz explained that studies with modest aims may reach saturation quicker than studies that span disciplines.

\section{Instrumentation}

The data for this study came from an interview with parents and health care providers concerning their beliefs about childhood asthma conditions, the use of prescribed medications, the risk of addiction to medicines, fear of medication side effects, the use of herbal medicine, and the economic impact of having a child diagnosed with asthma. The questionnaires for parents consisted of 17 open-ended questions based on the concepts of the HBM (see Appendix A and B). Each parent chose the appropriate language for the interview. 


\section{Data Collection Instrument}

For data collection, I used a 17-item questionnaire based on the six health belief

model concepts (see Appendix A and B). The questionnaire also contained the following demographic items: parents' age, ethnicity, place of birth, and age of the child. This information was needed to assess the inclusion criteria. The questionnaire was tested with two participants who met the inclusion criteria. The data from these test participants were not included in the study. The purpose of the pilot was to validate the questionnaire and determine whether any changes were needed. The IRB number for this study was 11-30$16-0136017$.

The second method of data collection was one focus group session with the health care professionals. Focus groups are widely used in qualitative studies; they include observations and interviews for data collection (Liamputtong, 2011). A focus group is a structured discussion concentrated on a single topic (Krueger \& Casey, 2000). The purpose of a focus group with the clinical staff in the current study was to increase the diversity of data obtained and to provide triangulation for the parents' data to ensure trustworthiness and credibility. The focus group participants received a summary of the study results through their e-mail address. The focus group questions are in Appendix A and $\mathrm{B}$.

\section{Procedures for Recruitment, Participation, and Data Collection}

The recruitment of the participants was based on the children's diagnosis of asthma by a licensed medical professional. To be included in the study, subjects needed 
to be a person of Puerto Rican descent age 18 years or older and a mother, father, or guardian of a child who met the following criteria:

- age 1 to 17 years

- diagnosed with asthma or severe asthma, and

- active recipient of asthma treatment including inhaled or oral bronchodilators and corticosteroids for 1 year.

The exclusion criteria were the following:

- parents not born in Puerto Rico,

- children with other severe lung comorbidities,

- children age less than 1 year or older than 17 years, and

- children not receiving corticosteroids as part of their asthma treatment.

Table 2 presents the types of data related to the interview questionnaire and focus group questions. 
Table 2

Overview of Data

\begin{tabular}{|c|c|c|}
\hline Type of Data & Methods & Health Belief Model Concept \\
\hline $\begin{array}{l}\text { (a) Demographics - Age, } \\
\text { Born Place Ethnicity }\end{array}$ & Interview & N/A \\
\hline $\begin{array}{l}\text { (b) Parental report of diagnosis, } \\
\text { medication usage, education, } \\
\text { route lung comorbidities }\end{array}$ & Interview & $\begin{array}{l}\text { Perceived Severity } \\
\text { Perceived Susceptibility }\end{array}$ \\
\hline $\begin{array}{l}\text { (c) Parental beliefs about } \\
\text { medications, side effects, } \\
\text { use of herbal medicine }\end{array}$ & Interview & $\begin{array}{l}\text { Perceived Benefits } \\
\text { Perceived Barriers }\end{array}$ \\
\hline $\begin{array}{l}\text { (d) Health care professionals' } \\
\text { view of the causes of low } \\
\text { medication compliance }\end{array}$ & $\begin{array}{l}\text { Focus } \\
\text { Group }\end{array}$ & Perceived Barriers \\
\hline $\begin{array}{l}\text { (e) Health care professionals' } \\
\text { cultural awareness }\end{array}$ & $\begin{array}{l}\text { Focus } \\
\text { Group }\end{array}$ & $\begin{array}{l}\text { Self-Efficacy } \\
\text { Cues to Action }\end{array}$ \\
\hline
\end{tabular}

A flier (see Appendix C and D) with the study information was placed in the medical office lobby area with the permission of the office administration. The flier was also placed on a Hispanic church's bulletin board. The only contact information on the flyer was my university e-mail address. Once the prospective study subjects contacted me, they went through a telephone screening process to assess the inclusion criteria. Once I validated that subjects met the inclusion criteria, they were invited to participate.

Audio-recorded interviews were conducted with eligible subjects using the questionnaire, which was available in English and Spanish. The interviews were conducted in person, and each took approximately one hour. After the subject responded 
to each question, I read back the answer to validate the accuracy of the data collected. This study did not require follow-up interviews with the subjects. The focus group was conducted with 3 health care providers. The data were transcribed and reviewed by focus group members before analysis. The participants received a summary of the study results through e-mail once the study was approved for publication. The results were written in nontechnical language.

\section{Data Analysis Plan}

Due to the small sample size of eight, the analysis of the data was done manually. Similarities and themes, including common words and ideas, were coded in connection with the corresponding research questions (see Ulin et al., 2005). The purpose of this process was to identify emerging themes. In qualitative research, there is no preestablished standard set of rules on how to code the data (Ulin et al., 2005). Once all familiar theme pieces were together, they were grouped by research questions. This format helps in the organization of the collected information and facilitate the analysis of the findings.

\section{Issues of Trustworthiness}

The use of two groups of respondents, parents and medical staff, helped to increase the internal validity of the study. The parents' questionnaire was validated by two parents, and no changes were made to the instrument. Data from these two subjects were included in the study. Triangulation involved the use of different methodologies, mainly observation, focus groups, and individual interviews, which account for most data 
collection in qualitative research (see Shenton, 2004). The data collected during the interviews and focus group were transcribed and reviewed by the participants.

Each parent or guardian had the opportunity to refuse to participate in the study. This was done to ensure that the data collection sessions involved only those who were willing to offer data freely (see Shenton, 2004). This strategy opens the channels of communication between the researcher and the study subject. The parent or guardian had the right to withdraw from the study at any time. The purpose of the study was disclosed at the beginning of the interview with the parent or guardian to promote the credibility of the study.

The strategies to establish transferability (external validity) included the use of a clinic that provided health services to asthmatic children of Hispanic origin. Participation was open to a specific group of parents or guardians, and the data collection methods were the same for every parent or guardian. Ulin et al. (2005) explained that "lessons learned from qualitative studies could be applied to other contexts if samples have been carefully selected to represent viewpoints and experiences that reflect key issues on the research problem" (pp. 146-147).

Dependability refers to whether one can track the processes and procedures used to collect and interpret data (Bloomberg \& Volpe, 2012). The utilization of a focus group and interviews helped in achieving dependability. The process of conducting the focus group and interviews is explained in the methodology section. This step enabled future researchers to repeat the work. The data are available for review by other researchers. 
Confirmability refers to the degree to which the results could be confirmed or corroborated by others (Trochim, 2006). To achieve confirmability, I used triangulation by collecting data from different sources. The first data source was the interviews with parents and caregivers, and the second data source was the focus group with the health care providers. Another strategy to achieve confirmability was my admission of my beliefs and assumptions as a means of achieving quality in the study (see Shenton, 2004). After the subject responded to each question, I read back the answer to validate the accuracy of the data collected.

\section{Ethical Procedures}

This study was guided by all the policies and procedures set by the Institutional Review Board of Walden University. The data collected were kept confidential and in a locked cabinet. Only I have access to this cabinet. No identifying information such as names or addresses was used in the study. The participation of the parents was voluntary. All participants were informed about their right to withdraw from the study at any time without any negative consequence. The data collection questionnaires were kept in a locked file cabinet. The audio recordings were transcribed into a document format and kept in a locked file cabinet. The study was not conducted at my workplace.

\section{Summary}

Chapter 3 contains a detailed description of the study methodology. This chapter also includes the strategies used to achieve trustworthiness, credibility, dependability, and transferability. The data collection instruments were a combination of previously validated questionnaire and focus groups. I used a qualitative method to explain why 
asthma medication adherence is low among Puerto Rican children. I also used this method to examine parents' perceptions and beliefs about their children's asthma therapy. The sample for this study was eight parents/guardians whose children had been diagnosed with asthma for at least one year and were between the ages of 1 and 17 years. I intended to explore parents' beliefs about asthma and asthma treatment. The findings from this study may help the caregivers to understand the dynamics of the Puerto Rican family and use that understanding to create a culturally appropriate asthma treatment plan. 
Chapter 4: Results

The purpose of this qualitative study was to explore parents' and health care providers' perceptions of asthma, asthma treatment, and how cultural beliefs may affect treatment compliance. This chapter includes descriptions of the pilot study, setting, participant demographics, and data collection findings. The data analysis and evidence of trustworthiness are also explained in this chapter. The chapter concludes with a summary and transition to Chapter 5 .

The research questions address in this study were the following:

1. What are the perceptions of Puerto Rican parents about asthma and its causes?

2. What are the perceptions of Puerto Rican parents about the asthma treatment recommended for their children?

3. What are the perceptions of health care professionals about the reasons for low asthma treatment medication compliance?

\section{Pilot Study}

To validate the study questionnaire, I conducted a pilot study with two subjects. No subsequent changes to the parent questionnaire or data collection strategies were made. The data collected during the pilot study were not included in the final results.

\section{Setting}

Due to the nature of their job and their work demands, two doctors and one physician assistant were unable to attend the focus group session. One of the study participants did not complete the interview due to the sudden illness of a close family member. Two subjects were emotionally touched during the meeting, and that was 
manifest by the presence of tears during the interview process. Both of them have been dealing with their children's asthma diagnosis since childbirth.

\section{Participants' Demographics}

All of the study subjects were born in Puerto Rico and live in the United States. Three participants were single parents, and five of them were married. The children's ages were between 6 and 17 years, with a mean age of 13 years. The mean age for the parents was 37 years. All of the subjects' children had been diagnosed with asthma by a doctor and were receiving treatment for their condition.

\section{Data Collection}

The data for this study were collected through a focus group with health care professionals and face-to-face interviews with eight parents of Puerto Rican origin who had children who were diagnosed with asthma for a year or more. The purpose of the interviews was to gain in-depth perceptions from the parents regarding their children's asthma condition, including how they felt when their child was diagnosed with asthma and how they have coped with the asthma condition, the treatment, and daily living activities. Also, they were asked about their major fear after their child was diagnosed with asthma, their fear of medication side effects, and whether they had used natural medicine. Asthma education, if any, was also addressed. Each parent's interview was conducted using a 17-item questionnaire. Mothers completed six interviews. One interview was completed by one father, and one was completed by both parents. The mean age for the parents was 37 years. The parents' place of birth, age, and children's ages are summarized in Table 3. 
Table 3

Study Participants' Age, Place of Birth, and Children's Age

\begin{tabular}{llll}
\hline Subject number & Age & Child's age & Place of birth \\
\hline 1 & 28 & 6 & Puerto Rico \\
2 & 48 & 17 & Puerto Rico \\
3 & 34 & 10 & Puerto Rico \\
4 & 36 & 12 & Puerto Rico \\
5 & 42 & 17 & Puerto Rico \\
6 & 34,33 & 14 & Puerto Rico \\
7 & 48 & 16,17 & Puerto Rico \\
8 & 33 & $8,8,12,16$ & Puerto Rico \\
\hline
\end{tabular}

All subjects met the inclusion criteria, and all children used asthma medication on a regular basis for more than a year. Table 4 summarizes the asthma medications used by the children.

Table 4

Asthma Medication used by the Participants' Children

\begin{tabular}{ll}
\hline Subject number & Asthma medication \\
\hline 1 & Albuterol, Pulmicort \\
2 & Pulmicort, Albuterol \\
3 & Albuterol, Oral Steroids \\
4 & Symbicort, Proventil \\
5 & Albuterol, Flovent, Prednisone \\
6 & Pulmicort, Albuterol \\
7 & Albuterol, Symbicort, \\
8 & Albuterol, Pulmicort
\end{tabular}

The data collection was done in a neutral place for the parent and the interviewer. The duration of the process, including consent signing and the interview, was around 45 
minutes. All of the subjects chose to have the interview in Spanish. At the end of the discussion, the study participants received a hypoallergenic pillow cover for their child.

Each interview was recorded using a digital recorder and saved on a passwordprotected computer that could be accessed only by me. Each interview was transcribed into English and saved as a Word document. All of the recorded data will be kept for 5 years and destroyed after that time.

The focus group was conducted with health care professionals who managed Hispanic children with asthma on a daily basis. This focus group discussion included seven questions in a dynamic and open conversation conducted by me. Three health care professionals participated in the focus group. The focus group was composed of a doctor, a pediatric nurse, and a respiratory therapist. They all specialized in the management of asthma and had experience treating children of Hispanic origin. Three additional members of the group canceled their participation at the last minute and subsequently declined to participate in the study. The focus group was conducted at a Public Library, and after the signed consent was completed, the activity took around 60 minutes. The recording of the focus group session was done using a digital recorder. The data were then transcribed into a Word document and saved on a password-protected computer that could be accessed only by me. The data will be kept for 5 years and destroyed after that time.

\section{Data Analysis}

The interview audio files were transcribed into a Word document. A separate file was assigned to each subject. A number from 1 to 8 was used to identify the study 
participants. I read all of the transcriptions several times to familiarize myself with the data. The focus group members were defined by their specialty (doctor, nurse, and respiratory therapist). The data were then manually coded and grouped according to each research question and the study's conceptual framework. Table 5 presents the emergent codes for each research question.

Table 5

Research Questions and Emergent Codes

\begin{tabular}{ll}
\hline Research Question & Emergent Codes \\
\hline RQ 1. What are the perceptions of Puerto & Limiting Disease, Complex Disease, \\
Rican parents about asthma and its & Genetic Disorder, Fear of the Unknown \\
causes? & \\
RQ 2. What are the perceptions of Puerto & Strong Immediate Side Effects/Changes in \\
Rican parents about the asthma treatment & Behavior, Fear of Medication Side \\
recommended for their children? & Effects, Adverse Effects or Death of the \\
& Child, Expensive Daily Treatment, and \\
& Unknown Medication Long-Term Effect \\
& in Major Organs or Child Behavior. \\
RQ 3: What are the perceptions of & Codes: Disease not well Understood, High \\
healthcare professionals about the reasons & Prevalence of Asthma, Low acceptance of \\
for low asthma treatment medication & Asthma as Chronic Disease, Low level of \\
compliance? & Literacy About Asthma.
\end{tabular}

Finally, themes were identified by adjustment and comparison of the codes. Eleven themes, by research question, are summarized below. These themes are presented in detail, with supporting data, in the Results section. 


\section{Parents' Perceptions of Asthma (RQ1)}

1. Theme 1: Children with asthma cannot live a normal life.

2. Theme 2: Children's asthma causes parents worry and challenges with work.

3. Theme 3: Parents believe that Asthma is a disease passed from generation to generation.

4. Theme 4: Parents believe that asthma is a disease requiring complex daily management.

\section{Parents' Perceptions of Asthma Medications (RQ2)}

1. Theme 5: Parents worry about the unknown effects of asthma on their children.

2. Theme 6: Asthma medications have immediate side effects on children including changes in behavior.

3. Theme 7: Parents fear the side effects of medication, including the effect on major organs and the death of the child.

4. Theme 8: Asthma medications are expensive even with a medication plan.

\section{Health Care Professionals' Perceptions of Asthma (RQ3)}

1. Theme 9: Parents are familiar with asthma due to the high prevalence of the disease.

2. Theme 10: Asthma is not well understood by parents; their knowledge is compromised.

3. Theme 11: Parents fail to see asthma as a chronic disease that requires daily medication. 


\section{Evidence of Trustworthiness}

Credibility refers to whether the participants' perceptions match the researcher's portrayal of them (Bloomberg \& Volpe, 2012). The disclosure of the purpose of the study to parent participants and focus group members enhanced credibility of the findings. Each participant had the opportunity to refuse to participate in the study. Once participants understood the purpose of the study, they signed the informed consent form.

Dependability refers to whether clear processes and procedures were used to collect and interpret data (Bloomberg \& Volpe, 2012). The use of a focus group and parent interviews as the method for data collection enhanced dependability of the findings. The use of a voice recorder was another way to ensure dependability by ensuring that the data were clear and accurate. Recordings allowed me to listen to the interviews several times to familiarize myself with the data. Permission to be recorded was granted by the participant before each interview began.

Transferability was achieved with support from a clinic that provided health services to asthmatic children of Hispanic origin. The other site that was used for study promotion was a religious organization where the Hispanic population gathers on a weekly basis. Ninety percent of the members of the religious organization used for the study are from Puerto Rico. The names of the organizations were not disclosed to protect the subjects' confidentiality. The participation was open to a specific group of parents or guardians, and the data collection method was consistent with all study subjects.

Confirmability refers to the degree to which the results can be confirmed or corroborated by others (Trochim, 2006). This was achieved through triangulation 
involving the use of different data collection methods. In this study, two groups were asked similar questions, one using interviews and one using a focus group, and the responses of the two groups were compared during the analysis. The interviews conducted with parents of asthmatic children were guided by a 17-item questionnaire. The focus group was conducted with health care professionals and guided by a sevenquestion protocol.

The data collected during the interviews were reviewed by each participant. Once each question had been answered, the researcher read the response back to the parent to validate the information. The read-back technique is widely utilized by health care professionals to validate medical orders and clinical data between professionals; this technique was used during the whole interview process. The data collected during the focus group was transcribed and sent to the participants for review and comments.

\section{Results}

The parents and focus group members' responses were carefully examined, coded, and analyzed thematically according to the research questions. The research questions addressed in this study were the following:

1. What are the perceptions of Puerto Rican parents about asthma and its causes?

2. What are the perceptions of Puerto Rican parents about the asthma treatment recommended for their children?

3. What are the perceptions of health care professionals about the reasons for low asthma treatment medication compliance? 
Eleven themes emerged from the interviews. I used the themes to organize the results. Themes 1 to 4 address research question 1, themes 5 to 8 address research question 2, and themes 9 to 11 address research question 3 .

\section{Theme 1: Children with asthma cannot live a normal life}

The interviewed parents reported that children cannot live a normal life due to their asthma diagnosis. As one of the parents said, "he can't play, he plays, but he cannot do, you know certain things like other children...he gets exhausted.” All the parents understood that having a child with asthma changes the whole family dynamic. One of the parents had a contingency plan in the house because all four children in the family have asthma. "Also, we have learned how to keep the respiratory therapy equipment clean. To avoid the kids to get sick...we do have a contingency plan at the house, to keep the respiratory equipment clean.” All the parents carry their children's medication with them at all times in case the child suffers an asthma episode.

\section{Theme 2: Children' asthma causes parents to worry and causes challenges with work}

Fifty percent of the parents in this sample reported that their children were diagnosed with asthma after birth or afterward and most reported that this caused distress. For example, "I was very worried and scared because he was one month old when he was diagnosed. It was very difficult for me.”

This stress has an economic impact. One parent reported being concerned about not being able to take care of the child while working out of the house, which resulted in only one parent being able to work to sustain the family. In order to work, most parents 
relied on grandparents, nannies, or daycares to take care of their child. One of the mothers reported that her child required closer care due to her child's asthma and early age of diagnosis. She hired a nanny, but because her child's health was not improving as expected, she was forced to resign from her job to take care of him and follow the treatment as prescribed. She reported the following: "he stay in the hospital since he born...Once discharged I hired a person that took care of him at home, but he was not improving... when he was six months old, I decided to stop working and take care of him at home." Another mother reported that she stopped working to take care of her daughter, whose asthma did not improve in six months. "Last year because of the health situation of my daughter I have to stop working and start taking Medicaid."

\section{Theme 3: Parents believe asthma is a Disease passed from generation to generation}

Parents think that asthma is a genetic disease and that the child got it from them or another family member. One parent felt guilty when her child was diagnosed with asthma right after birth. "I was scared because when I was little I was asthmatic and you suffer a lot when you have those attacks. He was a newborn because it was since he was a newborn when he started to develop the disease, and I was feeling guilty because he got it from me." Table 6 presents the relationship between a subject's asthma diagnosis and the frequency of asthma diagnoses in the subject's family. 
Table 6

Relationship Between Asthma Diagnosis and Familial Occurrence

\begin{tabular}{ll}
\hline Subject number & Occurrence \\
\hline Subject 1 & Self \\
Subject 2 & Self \\
Subject 3 & Self, maternal grandparents, uncles \\
Subject 4 & Grandmother \\
Subject 5 & Mother \\
Subject 6 & Mother \\
Subject 7 & Mother \\
Subject 8 & Uncles \\
\hline
\end{tabular}

\section{Theme 4: Parents believe asthma is a disease that requires complex daily management}

Most parents think that asthma is a disease that requires complex daily management due to the multiple tasks involved in the care of an asthmatic child. The care of an asthma patient involves making sure that the oral or inhaled medication is administered every four to six hours, or as prescribed by the doctor. The performing of a chest tapping exercise that removes secretions from the lungs, daily use of the peak flow meter device, and regular respiratory exercises are all a part of the daily asthma management routine. Cleaning of the respiratory equipment is also part of the routine. All of these tasks are performed by the parents or other family members.

Parents of asthmatic children changed their lifestyle to avoid unintentionally exposing their child to a harmful environment that could trigger an asthma attack. Potential triggers include carpets, animals like dogs and cats, strong odors, and types of food like peanuts, nuts, seafood, and food colorants. Drastic changes in temperature or 
heavy exercise can trigger an asthma attack in children. Parents feared what could happen to their child if they had an asthma attack when the parents were not with them. All of these parents feared that their child could suffer an asthma attack while the parent was not present. The child might stop breathing. "I worry because asthma is something serious because if he has a lack of respiration, he could die." Asthma is a complex disease that requires daily control of asthma triggers to avoid disease exacerbation or an asthma attack.

\section{Theme 5: Parents worry about the unknown effects of asthma on their children}

Seventy-five percent of the parents (6/8) were afraid that their child might stop breathing. As one mother said, "my child had an attack and was unable to breathe. It happens once, and he was hospitalized. As a mom, I was frustrated when you see kid coughing nonstop and unable to breathe." Another mother also expressed this same fear: "What really scared me if that my son would stop breathing and I don't know what to do (sobbing).”

Another parent reported her concern about her child's asthma turning chronic and that the treatment needed to be keep being increased. "That asthma turns more chronic, and they keep increasing different medications."

\section{Theme 6: Asthma medications have immediate side effects on children including changes in behavior}

The participants reported how they felt about the asthma medication and its effect on their children. The asthmatic parents also recalled their own experiences with asthma medicine. For example, one reported that "the secondary effects of this medication can be 
very severe because the heart is going very fast...I have experienced that on myself, and that is why I am worried." Another parent described the immediate effect that the medication albuterol has on his child, and how it worries him that he needs the medication despite it possibly having other effects on the child's body.

"What worries me was the albuterol, because I noticed that when I gave him the albuterol his chest was very fast, the palpitation was very fast, and how you feel when that happens...I was very worried. I am worried because it is your son and you don't want to have any other complication. As a father, the fact that he needs the medication and that can cause in some way, you know to accelerate his heart. He can have an attack or something like that. Although the fact is that he doesn't want the medication, he can't stay calm, and then, then we have to hold him in order for him to have the medication, and that really makes me feel very uncomfortable."

\section{Theme 7: Parents fear the side effects of medication, including the effect on major organs and the death of the child}

All drugs used for asthma can have secondary effects, and parents know this. Their fear of unknown long-term side effects was clearly described by a mother of two daughters who have suffered from asthma since early childhood.

My biggest worry and it maybe because of ignorance and is about the medication effect on her lungs her heart, to see if those organs were affected and as I told you with some medication I noticed they get very I don't know how to say the word is like accelerated and that happens to me too because I also suffer from asthma I am asthmatic, and they have to prescribe another medication they change the 
Albuterol for a PO medication and another location that doctors prescribe or something for like an allergic patient, and it was a similar to Albuterol a person that has certain sensitivity And that one does not cause any sensitivity. And every time I go to the doctor, I remind him that because her heart was very accelerated. Even the way she spoke change when she got the medication she was very, very ill.

The parents in this study were worried about the long-term effects of asthma medication on their child's vital organs. This was one mother's worries about the longterm impact on her daughter. "Because those asthma medications are very strong and you don't know what effect that may have on his organs." Another mom was concerned about the effect on her son's heart. "Some of those medications if I give it to him constantly his heart was very agitated." Another said, "My biggest worry and it maybe because of ignorance and is about the medication effect on her lungs her heart, to see if those organs were affected."

\section{Theme 8: Asthma medications are expensive even with a medication plan}

The cost of asthma medications for chronic care and a combination of corticosteroids, bronchodilators, leukotriene inhibitors, and steroids is estimated to be $\$ 300$ per month, though this cost could vary if the corticosteroids are prescribed by nebulizer inhalation or micro-powder. The type of prescription may depend on the child's age and dosage. Most of the interviewed parents said that, even with a medical plan, the cost of the medication co-pay was very high. One parent had to ask family members to buy the medication since they could not afford it: 
When we came to this country all the medications were covered by the medical plan. But in Puerto Rico, the Pulmicort and the albuterol was not covered anymore by the medical plan, and they were extremely high costly. We have to get help from family members telling them that we're asthma patients and to please give us their medications in order to be able to give the medication to my children.

Another parent had to ask the doctor for samples of the medications since the copay was very high and at least one or two samples would help to reduce the amount of money spent on asthma medications. "I have a medical plan, but even with that, the medication was very expensive the co-pay was very expensive. The primary physician always gives us samples; you know that help us a little bit."

The cost of asthma medical expenses was reported to be about $\$ 3,600$ per person, and that amount would have to be multiplied by the number of children with asthma in one family. Additional indirect costs are incurred when the child needs to stay home once they are sick, when they do not respond to treatment at home and need to be seen by a doctor, and when they need to be hospitalized. Parents need to use their vacation days; otherwise, they will not receive any pay for the time out of work while taking care of their child.

Theme 9: Parents are familiar with asthma due to the high prevalence of the disease Asthma is a complex disease that requires a lot of work from parents whose their sick children cannot provide self-care due to their age and development stage. The parents of asthmatic children in this study decreased the dosage of the asthma 
medications when their child was doing better or when they stopped coughing. The doctor who participated in the focus group explained how parents don't know the consequences of asthma:

One of the most common reasons is that parents don't know the real consequences of asthma and the real reason for the treatment, everybody used the treatment, but they don't know why, what the treatment is doing and so probably that's why when the patient feel better they stop treatment because they don't know how it works.

Asthma prevalence in Hispanic children is higher than in any other ethnic group. This is also seen in the families where the mother, father, grandparents are also asthma patients. They all grew up knowing asthma as a disease that is shared by mostly all members of the family, as stated by the focus group doctor:

I think Hispanic population is very used to live with asthma everybody has asthma, everybody has asthma is not normal and everybody lives with asthma, and that's not good because we're not supposed to live coughing and out of breath and not being able to do exercise. You're a kid you are supposed to be able to, but it's like normal they raised used to have asthma mean coughing and out of breath. Data triangulation showed that all the subjects in the study reported having a close family member diagnosed with asthma.

\section{Theme 10: Asthma is not well understood by parents}

A doctor in the focus group reported that some parents lack education about asthma, asthma medication, and medication administration. This information was 
validated when only $25 \%$ percent of the interviewed parents reported having received education about asthma. Some health care professionals struggled to warn parents that they were doing something wrong, but in reality, some parents do not know what they are doing. The doctor in the focus group reported the following:

I said, having a kid with asthma is like a normal thing, is hard to tell them you are doing something wrong with the treatment. What I do is trying to explain to them what is going on what is the difference between treatments, because people don't understand the difference between the nebulizer and the inhaler they think is all the same and is not.

\section{Theme 11: Parents fail to see asthma as a chronic disease that requires daily medication}

The participants of the focus group indicated that one of the most common situations they see in their practice is parents discontinuing the medication when they see improvement in the child's condition. This fact was reported by the respiratory therapist: "I think one of the main reasons is as soon as the patient feels better for the symptoms are not that bad then they stopped the treatment meaning if the patient feels better."

Another area discussed was the lack of understanding of asthma as a chronic

disease, as the respiratory therapist explained: "something that I see a lot is that they give the Duoneb that is a bronchodilator, but they need maintenance medication they need steroids, and they need something to keep them from having the attack."

Another factor frequently seen is the use of the ER for asthma treatment. Once the child's condition improves, they are discharged and instructed to follow up with the 
pediatrician. The parents then fail to take the child to a follow up, resulting in the child returning to the ER under similar circumstances. The respiratory therapist expressed the following: "they go to the ER they see the ED physician and ok I got my treatment, but when is time to see the pediatrician they don't follow up." The lack of a follow up after an asthma attack can place the child's life at risk increase the probability of returning to the ER with a more severe episode of asthma.

\section{Summary}

The purpose of this study was to examine the perceptions that parents of Hispanic children have about asthma, its causes, medication therapy, and the perceptions of health care professionals about the reasons for low asthma treatment compliance. Chapter 4 presents the data collection process and the results of the interviews of eight parents and three healthcare professionals. The selection of the participants was based on the asthma diagnoses of their children, the regular use of asthma medications, and the parents' place of birth. For the health care professionals, the selection was made based on their clinical experience in the treatment of asthmatic children of Hispanic origin. The parents and focus group members' responses were carefully examined, coded, and grouped according to the research questions. Based on similarities, 11 themes emerged from the data.

The parents were worried about their children's asthma diagnoses. They understood that asthma is a genetic disease that has been present in their family members from generation to generation. They all have changed their family dynamics to care for their asthmatic children. 
The use of asthma medication generated a lot of stress in parents. The medications' side effects, like tachycardia and hyperactivity, worried them. The unknown long-term effects of the asthma medication also concerned the parents. The high cost of asthma medication represents a burden on the parents' finances, even though all of the study subjects had a medical plan or received help from a government-funded medication plan.

The health care professionals understood the need for asthma education to help the parents to cope with their children's asthma diagnoses. The high prevalence of asthma in the Puerto Rican community cause parents to view asthma as a common disease, making it more difficult to educate the parents. This perspective represents a challenge to doctors, nurses, and respiratory therapists that deal with asthma exacerbations on a daily basis. In Chapter 5, I discuss the study findings, limitations, recommendations, implications for future research, and social change. The study conclusion is presented at the end of that chapter. 
Chapter 5: Discussion, Conclusions, and Recommendations

My purpose with this qualitative study was to explore parents' perceptions of asthma, its impact on the life of their child, and their experiences with asthma treatment prescribed for their child, including low adherence to asthma medication. I also explored the use of herbal medicine in addition to asthma medicine and health care professionals' beliefs of what could be the reason for low adherence to asthma medication. This study was conducted to understand the cause of low compliance with asthma medications according to the parents of Puerto Rican children diagnosed with asthma and to explore the perceptions of health care professionals about the reason for low compliance of asthma treatment. Puerto Rican children have the highest lifetime prevalence of asthma of any ethnic group (Lara, Akinbami, Flores, \& Morgenstern, 2006). In Chapter 5, I discuss the findings, limitations, recommendations for future research, and social change implications. The chapter ends with a conclusion.

\section{Interpretation of the Findings}

Three research questions were used to guide the study. The first addressed the perceptions of Puerto Rican parents about asthma and its causes. The second question addressed the perceptions of Puerto Rican parents about the asthma treatment recommended for their children. The third question addressed the perceptions of health care professionals about the reasons for low medication compliance during asthma treatment. Eleven themes emerged from the data analysis. The themes were grouped based on the research questions. 


\section{Theme 1: Children with asthma cannot live a normal life}

The parents' responses indicated that they were all worried after their children's asthma diagnoses. This feeling was most evident when the condition was diagnosed immediately after birth or during the early life of the child. Parents reported concern that their children could not live a normal life like other children, they could not play the same, and they could not attend school on a regular basis. Asthma caused 10.5 million missed school days and 14.2 million missed workdays in 2008 (CDC, 2014a). Children with asthma have reported missing school days due to an asthma exacerbation episode (CDC, 2014a). Despite the advances in the care of children with asthma, this disease still imposes a significant burden on the child population (Hossny et al., 2016). An early onset of asthma has an extended health effect on a child's lungs, affecting his or her capacity to breath; this is a risk factor of asthma continuing into adulthood (Hossny et al., 2016). Parents indicated that the family dynamics change after an asthma diagnosis. The need for daily medications, respiratory treatments, costly medications, and high co-pays affects the family as a whole.

\section{Theme 2: Children's asthma causes parents to worry and causes challenges with work}

Parents reported being forced to miss work or quit their jobs to take care of their sick child. This affected the family financially because only one parent was working. Parents also reported leaving their children with a close family member like a grandmother to be able to work. A child being sick for an extended period was also a challenge for the single mothers who need to work. Parents stay awake, sometimes all 
night, taking care of a sick child, interrupting the parents' sleep cycle and directly impacting their ability to work and have a healthy social life (Lenney, 1997).

\section{Theme 3: Parents believe that Asthma is a disease passed from generation to generation}

All of the parents who participated in the study had a close family member with a history of asthma. This family member was a child, grandmother, grandfather, aunt, uncle, or great grandparent. Parents felt in some way guilty because many of the parents had asthma as well. Most of them were diagnosed with asthma in early childhood. Children with parents and grandparents with asthma are 4 times more likely to have asthma when compared with children with parents or grandparents without asthma (Valerio et al., 2010). The disclosure of the asthma history in the family could be a tool for identifying asthma in early childhood and determining the need for diagnostic assessment (Valerio et al., 2010).

\section{Theme 4: Parents believe that asthma is a disease that requires complex daily management}

The parents in this study reported that they had a daily routine that included medication administration every morning before school, medication at school administered by the school nurse, medication before any sports activity, and medication before bed. The daily management also included cleaning the house, keeping it free of dust, and avoiding highly allergenic foods like peanuts, cashews, soy, or seafood. The planning of family outings to avoid unintentional exposure to environmental allergens was part of the family routine. The triggers for asthma include pollen, mold, animal 
dander, dust mites, and cockroaches (Canino et al., 2006). Other known triggers are airway infections and exposure to toxic chemicals such as smoke from tobacco and pollution from automobile exhaust (CDC, 2014a).

\section{Theme 5: Parents worry about the unknown effects of asthma on their children}

Another source for parental anxiety was the asthma medications' side effects and the unknown long-term effects that the treatment would have on their children. This was evident after the administration of bronchodilators and the immediate impact that it had on a child's heart or other major organs. The parents were concerned about how an extended use of asthma medication could affect their children's mental health. The treatment of asthma included the daily use of corticosteroids and long-acting betaagonists (AAAAI, 2014b). Short-acting beta-agonists are used when immediate relief is needed (AAAAI, 2014b). The direct effects of asthma medications are classified by the type of medication use. For inhaled corticosteroids, the local side effects are oropharyngeal candidiasis and dysphonia; high doses of inhaled corticosteroids increase the risk for systemic side effects like osteoporosis (GINA, 2018). Short-acting beta agonists (SABA) can cause tremors and tachycardia, and excessive use of or limited response to SABA indicates uncontrolled asthma (GINA, 2018).

The combination of a long-acting beta-agonists and inhaled corticosteroids such as formoterol and fluticasone is associated with tachycardia, headaches, and abdominal pain (GINA, 2018). Some of the adverse effects of short-term systemic use of steroids (tablet, suspension, intramuscular or intravenous injection) include sleep disturbance, reflux, increase appetite, hyperglycemia, and mood changes (GINA, 2018). The long- 
term effects of this type of medication include cataract, glaucoma, osteoporosis, and adrenal insufficiency (GINA, 2018).

\section{Theme 6: Asthma medications have immediate side effects on children including changes in behavior}

All of the parents reported that one main concern was the effect of bronchodilator use on their children. The asthma medication's side effects and the unknown long-term effects that the treatment can have on their child were sources of anxiety for the parents. This was evident after the application of bronchodilators and the immediate impact that medications have on the child's heart or principal organs. The parents also reported concern about how an extended use of asthma medications could affect their children's mental health.

The main side effect parents mentioned during the interviews was tachycardia and hyperactivity. These effects created a lot of tension and concern in the parents due to the need for the medication to improve the child's asthma status despite side effects on the cardiovascular system. Some of the side effects associated with the use of SABA and long-acting beta-agonists are tremors, tachycardia, hyperactivity, headaches, and abdominal pain (GINA, 2018).

The use of herbal medicine was explored as part of this study. A few parents reported the use of herbal medicine. These parents found it useful, especially to help their children sleep while sick with asthma. Seventy-five percent of the parents had tried herbal medicine in conjunction with asthma medication and had found that it helped the child to breathe and sleep better. One parent stopped the asthma medication and used 
only the herbal medicine at least one time; she continues to use asthma medication but reported it is not her first choice. $75 \%(6 / 8)$ of the parents reported that they have use asthma medications in conjunction with herbal medicine. $25 \%(2 / 8)$ of the parents reported that they have only used asthma medications. Table 7 shows the type of herbal medicine used in conjunction with asthma medicine.

Table 7

Types of Herbal Medicine used in Conjunction with Asthma Medications

\begin{tabular}{lll}
\hline Herbal medicine & Frequency
\end{tabular}

\begin{tabular}{lcc}
\hline *Mejunje & $(3 / 6)$ & $50 \%$ \\
Eucalyptus & $(1 / 6)$ & $12 \%$ \\
Honey, lemon, garlic & $(1 / 6)$ & $12 \%$ \\
Ginger tea & $(1 / 6)$ & $12 \%$
\end{tabular}

Note. ${ }^{*}$ Homemade concoction that includes aloe, onions, pure honey, witch hazel, and lemon.

Six parents reported that they had used herbal medicine as part of the asthma treatment for their children. Five parents used herbal medicine in conjunction with doctor-prescribed asthma medicine. Only one parent stopped the asthma medication to use only the herbal medicine for their children's asthma for a brief period of time.

\section{Theme 7: Parents fear the side effects of medication, including the effect on major organs and death of the child}

All of the parents were concerned about the side effects of asthma medication; they also expressed concern about what would happen if the child stopped breathing. Parents reported that they did not know the long-term effects of the medicines on 
children's vital organs like the heart or brain. Parents were also concerned about asthma's impact on the children's mental health, including their emotions.

Even though parents expressed fear of asthma medications' side effects, they never stopped the medical treatment of their child. One parent reported that when her child is sick she tried herbal medicine first and then asthma medications. Some parents reported that they had reduced the frequency of the medication regimen due to the change in the behavior of the child, like episodes of hyperactivity and tremors. All of the parents reported that their children exhibited hyperactive behavior after use of asthma medications.

Parents' literacy about asthma played a significant role in child treatment. The diagnosis of asthma was very stressful. Findings suggest that an open dialogue should occur between parents and health care professionals to decrease the anxiety that this condition may pose for the parents and children. This may help to minimize the negative impact (Patterson, 2013). Partnerships among health care providers, nurses, and therapists are crucial to make sure that the family feels comfortable working with the health care team (Garro, 2011).

\section{Theme 8: Asthma medications are expensive even with a medication plan}

All parents reported that asthma medications are costly, and even with a medical plan the co-pay is still very high. Parents who have government plans like Medicaid or state specific medical plan may have a lower co-pay. Some parents rely on other asthmatic family members to get the medications. One parent used herbal medicine when possible as an alternative to the high cost of asthma medications. Medical samples were 
another option reported by parents. The parents' socioeconomic status plays a vital role in the asthma control of their children. The availability of the medications, either through private or government medical plans, is crucial because asthma is a chronic disease that requires daily medications. The parents in the study reported having access to a medical plan to maintain the child' asthma treatment. Asthma treatment in the United States costs an estimated \$3,100 per year per household (Nunes, Pereira, \& Moralys-Almeida, 2017). Theme 9: Parents are familiar with asthma due to the high prevalence of the disease

The health care professionals that participated in the study reported that, due to the high prevalence of asthma in the Hispanic population, most parents see asthma as a regular thing. The primary concern of healthcare professionals is that the parents do not know the consequences of asthma. The familiar pattern of asthma is a prevalent scenario seen by health care professionals in their daily practice. Numerous biological, social, and environmental risk factors explain the high prevalence of asthma in Puerto Rico; some of these elements include socioeconomic status, psychosocial stress, and pollution (Kopel et al., 2014). Biological factors and a family history of asthma were also studied because these factors make children four times more likely to develop asthma than other children (Valerio et al., 2010).

Asthma is more prevalent in African Americans and Puerto Ricans. Puerto Rico has a mixed population of African, European, and Native American ancestry (Martinez et al., 2005). All of the parents who participated in the study have one or more close relatives diagnosed with asthma. When compared with other countries like Austria, 
France, Finland, Germany, Italy, and Spain, Puerto Rico has the highest asthma mortality rate (Bartolemei et al., 2011).

\section{Theme 10: Asthma is not well understood by parents}

The focus group participants identified asthma in the Hispanic population as a familial disease. Hispanic parents require a lot of education to understand the importance of continual asthma treatment. This finding parallel parents' disbelief that they were not educated or offered resources when their child was diagnosed with asthma. The frustration that the lack of education creates was evident. Social media and other online sources were used by the parents to gather information about asthma, asthma medications, and side effects.

Only two unrelated parents reported that they had received an asthma medication plan and disease education after their child was diagnosed with asthma. The children of both parents received their asthma diagnosed in the United States. The rest of the parents did not receive any education about asthma or asthma medication, and they were diagnosed with asthma while living in Puerto Rico. One of the parents learned about the disease due to an internet search; another parent talked about the condition with their asthmatic parents and grandparents. According to Healthy People 2020 RD-7.1, one of the goals for the year 2020 is to increase the practice of giving persons diagnosed with asthma a written plan to manage their asthma from their health care provider (ODPHP, 2018).

Patients can prevent asthma attacks if they are educated about the proper use of asthma medications, including bronchodilators and the daily use of inhaled corticosteroid 
(CDC, 2014b). Doctors and parents can better manage their children's asthma by creating an asthma action plan that the parents can follow (CDC, 2014b). According to GINA, patients should be provided with an asthma action plan suitable for their disease level and health literacy. The asthma action plan can help patients and caregivers to know what to do in case of an asthma exacerbation. The plan should include information like asthma medications, when to increase the dosage and oral steroids, and how to access medical care in case of asthma exacerbation (GINA, 2018).

Knowledge of asthma can translate into a better understanding of the disease and the physiological mechanisms that occur during an asthma attack. Educating the parents on how to modify the immediate environment to reduce the probability of an asthma attack is crucial due to the strong association between asthma and the environment. This can be accomplished by educating parents on how to manage their children's asthma symptoms and creating a plan to follow in the different phases of an attack.

\section{Theme 11: Parents fail to see asthma as a chronic disease that requires daily medication}

The focus group with the health care providers was an essential part of this study. The focus group members reported that many parents stopped the medication when their children's symptoms lessened. They used bronchodilators when the child had an asthma attack, but once the episode was solved, they did not use a corticosteroid on a regular basis. These were evident due to the number of patients they see in the ER with asthma exacerbation and readmissions of the same patients. 
This pattern of constantly visiting of the ER when the patient has an asthma attack is most seen in children of low socioeconomic status due to economic disadvantage and non-compliance with asthma medications (Nunes et al., 2017). This pattern could also be due to the lack of medical equipment at home (nebulizer machine) or a lack of control of trigger factors such as dust, respiratory infections, and environmental irritants (Nunes et al., 2017).

Even though the parents expressed their fear of asthma medications' side effects, they never stopped the medication treatment. Some parents reduced the frequency of the medication regimen due to a change in the behavior in their children, like episodes of hyperactivity or increased heart rate. All of the parents related their children's behaviors to the use of bronchodilators.

\section{Limitations of the Study}

In this qualitative study, I relied on the responses of parents and health care professionals about children's health and treatment compliance. I relied on the sincerity of the parents and them feeling comfortable expressing their thoughts and fears. Some of the information given by the parents may not be verified; for instance, the medications they used could not be validated because they did not carry their children's medication to the interview.

In relation to the study questionnaire, an area not included during data collection was whether the child was seen by a pediatrician, primary doctor, or pulmonologist. Knowing the physicians' levels of specialization, I could have had a better idea of the type of services received, the severity of the child's asthma condition, and from what 
level of care the education was obtained. That information may have helped me to evaluate the services received and whether there was any gap in education strategies.

Another limitation was that the children's asthma severity levels were not

included in the study. Evaluating asthma severity is better suited for quantitative research. For that reason, a mixed methods study should be conducted on similar topics in the future. Another limitation was the inability of some parents to attend the interview session due to not having a responsible person to take care of the children while doing the interview. Other type of interview methods, such as telephone calls and Skype meetings, should be explored when interviewing parents of children with any disease.

The same limitation was seen in the focus group session. The logistics involved with this type of group represented a significant challenge when trying to get health care professionals with different schedules and practices to be together at the same time in the same place. A teleconference could be a better strategy for future studies in which the participation of multiple professionals is required.

Using a population that was composed of only one ethnicity was another limitation. The results of the study can only be attributed to this population. For future studies, other ethnicities should be included to help understand the asthma phenomenon among children.

\section{Recommendations}

Recommendations for future research include conducting a mixed methods study on a similar topic. The incorporation and study of other ethnicities like Mexicans, Cubans, and African Americans could help investigators to understand why asthma is 
more prevalent in those populations. The inclusion of non-medication compliant parents should be part of the criteria for the recruitment of subjects. A strategy to validate the adherence to medications should include monitoring the bronchodilator inhaler dosage marker, the filling of medication prescriptions at the pharmacy, and the number of hospitalizations, physician visits, and emergency room visits by the patients. Demographic factors like parents' education, marital status, and socioeconomic status should also be considered. All of these variables should be evaluated when planning a mixed methods study. A questionnaire about parents' asthma literacy can be used to measure parents' knowledge about asthma and asthma medications. The information collected from this type of questionnaire may reveal whether any asthma education was provided to the parents, who provided the education, and how effective the education was in decreasing the asthma episodes of their children. This type of study could be also done for other groups such as adults with asthma. A mixed methods study may allow investigators to visualize a problem from different perspectives while helping to increase the knowledge and body of evidence most needed to decrease health care disparities.

\section{Implications}

Asthma is a chronic disease that affects children and adults around the world. Hispanic children have the highest prevalence of asthma, and the reason for this phenomenon is not well understood. Being diagnosed with asthma at an early age disturbs parents, family dynamics, and a family's way of life. The parents' need for asthma education was evident from the findings of this study. An implication for social change derived from the findings is the recognition that education about asthma, asthma 
treatment, and the adequate use of medication delivery devices by a health care professional is vital when a child is diagnosed with asthma. Given that asthma is a chronic condition, education may aid in the reduction of parents' frustrations and a better understanding of disease management. Educating parents may improve their children's health and affect their use of health care services. Fewer medical office visits, ER visits, and fewer hospitalizations are some of the effects that parental asthma education can have. An educated parent may recognize the signs and symptoms an asthma exacerbation episode. Knowing how to act under that circumstance may prevent an acute attack. Asthma education may help parents to have healthy coping mechanisms for their child's disease.

Increasing parents' knowledge about asthma may also help reduce school absenteeism and lost days of work. Furthermore, it may increase the number of asthmatic children participating in sports and physical education classes at school. Understanding the spectrum of asthma in the Puerto Rican community will help physicians and health care professionals to deliver an asthma education program tailored to the needs of the Hispanic population. The massive migration of Puerto Ricans to the United States after Hurricane Maria destroyed the island in September 2017 is clear evidence of the need to be prepared to serve this population. Having knowledge of patients' cultural backgrounds and beliefs may help health care professionals to better aid patients and families. The emotional cost of asthma cannot be measured, but we can help parents to understand what asthma is and how they can manage their children's disease exacerbation. Parental asthma education is vital for the health of the children and the wellbeing of the family. 
Further research is needed to explain this health care disparity. Future investigators should conduct mixed methods studies to evaluate the reasons for non-adherence to asthma medication, the lack of parental education, and parental beliefs about asthma. The recognition of the burden of asthma in the Hispanic community may help organizations like the CDC, GINA, and the American Academy of Asthma and Immunology to delineate plans to deal with the asthma burden of this population and to fund programs for the promotion of asthma education for children, parents, schools, communities, and countries around the world.

\section{Conclusion}

The purpose of this qualitative study was to explore the perceptions of Puerto Rican parents and health care professionals regarding asthma, its cause, and implications I explored the perceptions of Puerto Rican parents about their children's asthma treatment and the perceptions of the health care workers about the reasons for low asthma treatment adherence. My motive for conducting this study was to help others understand why asthma is a burden in the Puerto Rican community from a qualitative perspective. The theoretical framework used in this study was the HBM and the IOM's model framework for asthma disparities. The HBM is composed of six perceptions: perceived seriousness, perceived susceptibility, perceived benefits, perceived barriers, cues to action, and selfefficacy.

The results of this study suggest several important facts about this population. The parents' interviews showed that all the parents understood the seriousness of asthma and the implications for their children's health. Perceived barriers to medication compliance 
were found in the burden that the asthma medication regimen represents for the parents, regarding its high cost and high copay for those with a prescription medical plan. Most parents understood the benefits of following the medication regimen but reported frustration at not being educated more about asthma by their primary care physician. Selfefficacy was highly compromised because $75 \%$ of the parents reported that they had not received any type of education about asthma or an asthma action plan. Cues to action were also compromised because parents did not know what to do in case of an emergency; parents mostly relied on the use of hospital emergency services or 911 to receive care in case of an asthma critical episode in their children. The parents of this study relied on social media, Google searches, and Wikipedia to learn about asthma, asthma medication treatment, and what to do in case of an asthma exacerbation.

As reported earlier, the IOM's model suggests that no single factor is a primary cause for the health disparity for asthma among children in Puerto Rico. The results of this study confirm that finding. The IOM also emphasizes the importance of providerpatient interaction in quality of care, and this study shows that provider-patient interactions were minimal for this population. The causes of this were not examined in this study; but, according to the Centers for Disease Control (2014b), asthma education is key. Patients can prevent asthma attacks if they are educated about the proper use of asthma medications, including bronchodilators and the daily use of inhaled corticosteroid (CDC, 2014b). The findings of the current study suggest that, despite their fears of the medications' side effects, Puerto Rican parents do not stop giving the medication to their children. They find medication to be very costly and the side effects tough to deal with. 
However, they understand that the children need asthma medication to get better. The use of herbal medicine was a helpful alternative for a few parents, especially if their parents and grandparents used herbal medicine, but not for all of them. In the vast majority of cases, the parents report that herbal medicine helped their children to sleep and breathe better.

Education about asthma is critical for a parent once a child receives an asthma diagnosis. Unfortunately, this study revealed that Puerto Rican parents who came from Puerto Rico to live in the state of Florida did not receive any education about asthma or asthma treatment at the moment the child was diagnosed with asthma. Furthermore, these parents did not have an asthma education plan in case of an asthma exacerbation. Doctors and parents can better manage children with asthma by creating an asthma action plan that the parents can follow (CDC, 2014b).

According to GINA, patients should be provided with an asthma action plan suitable for their disease level and health literacy. Asthma action plans can help patients and caregivers to know what to do in case of an asthma exacerbation. These plans should include information like asthma medications, when to increase the dosage and oral steroids, and how to access medical care in case of asthma exacerbation (GINA, 2018).

Lack of air and difficulty breathing are some of the symptoms of an asthma episode. Asthma symptoms can place a lot of stress on the parents, but if they are educated in asthma management, they can control the symptoms. The lack of parental education about asthma from the primary doctors and pediatricians could represent a 
challenge in the management of asthma at home if the parents are not well educated in how to manage their children's condition.

An asthma diagnosis can cause a lot of stress and frustration in parents, and that frustration and anxiety may multiply when they do not understand the disease etiology, medication regimen, and side effects. The parents' burden of asthma cannot be measured in dollars and cents. Health care professionals need to take time to educate parents to maximize the treatment effectiveness and to help these children to return to their normal living activities by decreasing the length of sickness and asthma episodes.

Asthma will always be a chronic disease that cannot be cured. Parental education about asthma should be mandatory for new asthma diagnoses. Having knowledge about asthma, asthma action plans, medications, and how to live with an asthmatic child may help the parents and children to understand the disease, know what to do in case of an asthma attack, and how to prevent an asthma episode by controlling external factors that may trigger disease exacerbation. The diagnosis of asthma in a child should not be a reason to change the family dynamics. Even though asthma is a chronic condition, with adequate education and proper use of resources, asthmatic children and their families can live a healthy and productive life. 


\section{References}

Akinbami, L. J., Moorman, J. E., Garbe, P. L., \& Sondik, E. J. (2009). Status of childhood asthma in the United States, 1980-2007. Pediatrics, 123(Suppl. 3), S131-S145. doi:10.1542/peds.2008-2233C

American Academy of Allergy, Asthma, and Immunology. (2013). Childhood asthma. Retrieved from https://www.aaaai.org/conditions-and-treatments/conditionsdictionary/Childhood-(pediatric)-Asthma

American Academy of Allergy, Asthma, and Immunology. (2014a). Asthma overview. Retrieved from http://www.aaaai.org/conditions-and-treatments/asthma.aspx American Academy of Allergy, Asthma, and Immunology. (2014b). Treatment and management of asthma. Retrieved from http://www.aaaai.org/conditions-andtreatments/asthma.aspx

American Academy of Allergy, Asthma, and Immunology. (2014c). Asthma statistics. Retrieved from https://www.aaaai.org/about-aaaai/newsroom/asthma-statistics American Academy of Allergy, Asthma, and Immunology. (2018). Corticosteroids definition. Retrieved from https://www.aaaai.org/conditions-andtreatments/conditions-dictionary/inhaled-corticosteroids

American Lung Association.(2014). Particle pollution. Retrieved from https://www.lung.org/our-initiatives/healthy-air/outdoor/air-pollution/particlepollution.html

Ayele, A., \& Getachew, H. (2017). Non adherence to inhalational medications and associated factors among patients with asthma in referral hospital in Ethiopia, 
using validated tool TAI. Asthma Research and Practice, 3(7), 1-6.

doi:10.1186/s40733-017-0035-0

Bartolomei-Díaz, J. A., Hanisch, R., Ruiz-Serrano, K., Irizarry-Ramos, J., MontalvoFeliz., I., \& Acevedo, E. (2017). Asthma mortality in Puerto Rico 2010-2015. Technical report, Puerto Rico Asthma Program, Puerto Rico Department of Health. Retrieved from http://nebula.wsimg.com/891b259829668d38dce 0c4631549646b? AccessKeyId=036DD2B5D5CF18C9F639\&disposition=0\&allo worigin $=1$

Bartolomei-Díaz, J. A., Amill-Rosario, A., Claudio, L., \& Hernández, W. (2011) Asthma mortality in Puerto Rico: 1980-2007. Journal of Asthma, 48(2), 202-209. doi: $10.3109 / 02770903.2010 .528498$

Black, P. (2002). Stress and the inflammatory response: A review of neurogenic inflammation. Brain, Behavior and Immunity, 16(6), 622-653. doi:10.1016/S0889-159(02)00021-1

Bloomberg, L. D., \& Volpe, M. (2012). Presenting methodology and research approach. In Completing your qualitative dissertation: A road map from beginning to end (2nd ed., pp. 112-113). London, England: Sage.

Boskey, E. (2016). Health belief model use of a condom may hinge on perceived risk. Retrieved from https://www.verywellmind.com/health-belief-model-3132721

Boulet, L. P. (1998). Perception of the role and potential side effects of inhaled corticosteroids among asthmatic patients. Chest, 113(3), 587-592. doi:10.1378/chest.113.3.587 
Brown, W., Ottney, A., \& Nguyen, S. (2011). Breaking the barrier: The health belief model and patient perceptions regarding contraception. Contraception, 83(5), 453-458. doi:10.1016/j.contraception.2010.09.010

Burgess, S., Sly, P., \& Devadason, S. (2011). Adherence with preventive medication in childhood asthma. Pulmonary Medicine, 2011, 1-6. doi:10.1155/2011/973849

Canino, G., Koinis-Mitchell, D., Ortega, A. N., McQuaid, E. L., Fritz, G. K., \& Alegria, M. (2006). Asthma disparities in the prevalence, morbidity, and treatment of Latino children. Social Science \& Medicine, 63(11), 2926-2937. doi:10.1016/j.socscimed.2006.07.017

Canino, G., Vila, D., Normand, S. T., Acosta-Pérez, E., Ramírez, P., García, P., \& Rand, C. (2007). Reducing asthma health disparities in poor Puerto Rican children: The effectiveness of a culturally tailored family intervention. American Academy of Asthma Allergy \& Immunology, 121(3), 665-670. doi:10.1016/j.jaci.2007.10.022

Canino, G., McQuaid, E. L., Alvarez, M., Colon, A., Esteban, C., Febo, V., ... Fritz, G. (2009). Issue and methods in disparities research: The Rhode Island Asthma Center. Pediatric Pulmonology, 44(9), 899-908. doi:10.1002/ppul.21075

Canino, G., McQuaid, E. L., \& Rand, C. S. (2009). Addressing asthma health disparities: A multilevel challenge. Journal of Allergy and Clinical Immunology, 123(6), 1209-1219. doi:10.1016/j.jaci.2009.02.043

Centers for Disease Control and Prevention. (2007). National Surveillance for AsthmaUnited States 1980-2004. Morbidity and Mortality Weekly Report. 
Centers for Disease Control and Prevention. (2009). Asthma: A Presentation of Asthma Management and Prevention. Retrieved from https://www.cdc.gov/asthma/speakit/default.htm

Centers for Disease Control and Prevention. (2012) Asthma Action Plan Definition. Retrieved from https://www.cdc.gov/asthma/actionplan.html

Centers for Disease Control and Prevention. (2014a). Asthma Impact on the Nation. Asthma Fact Sheet. Retrieved from http://www.cdc.gov/asthma /impacts_nation/default.htm

Centers for Disease Control and Prevention. (2014b). National Asthma Control Program; an Investment to American Health. Retrieved from http://www.cdc.gov/asthma/nacp.htm

Centers for Disease Control and Prevention. (2014c). Behavioral Risk Factor Surveillance System (BRFSS). Asthma prevalence and trends data. Retrieved from https://www.cdc.gov/brfss/

Centers for Disease Control and Prevention. (2014d). Stats about missed school days. Retrieved from https://www.cdc.gov/asthma/asthma_stats/AstStatChild_ Missed_School_Days.pdf

Centers for Disease Control and Prevention. (2017). Stats about asthma. Retrieved from https://www.cdc.gov/nchs/fastats/asthma.htm

Centers for Disease Control and Prevention. (2018). Asthma. Retrieved from https://www.cdc.gov/asthma/ 
Champion, V. L., \& Skinner, C. S. (2008). The health belief model. Health behaviour and health education: theory, research, and practice (pp. 45-65). San Francisco, CA: Jossey-Bass.

Charmaz, K. (2006). Constructing grounded theory: A practical guide through qualitative analysis. Thousand Oaks, CA: Sage.

Choudhury, A. H., Gordian, M. E., \& Morris, S. S. (1997). Associations between respiratory illness and PM10 air pollution. Archives of Environmental Health: An International Journal, 52(2), 113-117.

Conn, K. M., Halterman, J. S., Lynch, K., \& Cabana, M. (2007). The impact of parents’ medication beliefs on asthma management. Pediatrics, 120(3), e521-e526. doi:10.1542/peds.2006-3023

Departamento de Salud. (2018). Asthma Data Puerto Rico. Retrieved from http://nebula.wsimg.com/f58b4ebcdd3b5f9fe1512e6f436f0277?AccessKeyId=03 6DD2B5D5CF18C9F639\&disposition=0\&alloworigin $=1$

Ernst, E. \& Posadzki, P. (2012). Alternative therapies for asthma: Are patients at risk? Clinical Medicine, 12(5), 427-9. doi: 10.7861/clinmedicine.12-5-427

Escarce, J. J., Morales, L. S., \& Rumbaut, R. G. (2006). The health status and health behaviors of Hispanics. In M. Tienda \& F. Mitchell (Eds.), Hispanics and the future of America (pp. 362-409) Washington, DC: National Academies Press (U.S.). Retrieved from: https://www.ncbi.nlm.nih.gov/books/NBK19899/

Flores, G. (2000). Culture and the patient-physician relationship: Achieving cultural competency in health care. Journal of Pediatrics, 136(1), 14-23. 
doi: 10.1016/S0022-3476(00)90043-X

Garro, A. (2011). Coping patterns in Latino families of children with asthma. Journal of Pediatric Health Care, 25(6), 347-354. doi:10.1016/j.pedhc.2010.04.005

Gaude, G. S., Hattiholi, J., \& Chaudhury, A. (2014). Role of health education and selfaction plan in improving the drug compliance in bronchial asthma. Journal of Family Medicine and Primary Care, 3(1), 33-38. doi: 10.4103/2249-4863.130269

Gillette, C., Carpenter, D., Ayala, G., Williams, D., Davis, S., Tudor, G., ... Sleath, B. (2013). Clinical Pediatrics, 52(12), 1161-1167. doi:10.1177/0009922813506256

Glanz, K., Rimer, B., Vismanath, K. (2008). The health belief model. In Health Behavior and Health Education (p. 46). San Francisco, CA: Jossey-Bass.

Global Initiative for Asthma. (2018). 2018 GINA Report, Global Strategy for Asthma Management and Prevention. Retrieved from https://ginasthma.org/

Green, J., \& Britten, N. (1998). Qualitative research and evidence based medicine. BMJ, 316(7139), 1230-1232. doi:10.1136/bmj.316.7139.1230

Halterman, J. S., Aligne, C. A., Auinger, P., McBride, J. T., \& Szilagyi, P. G. (2000). Inadequate therapy for asthma among children in the United States. Pediatrics, 105, 272-276.

Horne, R., Weinman, J., \& Hankins, M. (1999). The beliefs about medicines questionnaire: the development and evaluation of a new method for assessing the cognitive representation of medication. Psychology \& Health, 14:1, 1-24. doi:10.1080/08870449908407311 
Hossny, E., Rosario, N., Lee, B. W., Singh, M., El-Ghoneimy, D., Soh, J. Y., \& Le Souef, P. (2016). The use of inhaled corticosteroids in pediatric asthma: update. The World Allergy Organization Journal, 9(1), 26. doi:10.1186/s40413-0160117-0

Joseph, D. H., Griffin, M., \& Sullivan, E. D. (2000). Videotaped focus groups: Transforming a therapeutic strategy into a research tool. Nursing Forum, 35(1), 15. doi: 10.1111/j.1744-6198.2000.tb01173.x

Kochhar, R., Gaviria, R., \& Ballas-Traynor, L. (2012). The growing U.S. Hispanic population: Impact on the U.S. economy and business. Retrieved from https://2009-2017-fpc.state.gov/190931.htm

Koinis-Mitchell., McQuaid, E., Friedman, D., Colon, A., Soto, J., \& Canino, G. (2008) Latino caregivers' beliefs about asthma: Causes, symptoms, and practices. Journal of Asthma, 45(3), 205-210. doi:10.1080/02770900801890422

Koinis-Mitchell, D., McQuaid, E. L., Kopel, S. J., Esteban, C. A., Ortega, A. N., Seifer, R., ... Fritz, G. K. (2010). Cultural-related, contextual, and asthma-specific risks associated with asthma morbidity in urban children. Journal of Clinical Psychology in Medical Settings, 17(1), 38-48. doi:10.1007/s10880-009-9178-3

Kopel, L. S., Phitapatanakul, W., Gaffin, J. M. (2014). Social disadvantage and asthma control in children. Pediatric Respiratory Review, 15(3), 256-263. doi:10.1016/j.prrv.2014.04.017

Krueger, R. A., \& Casey, M. A. (2000). Focus groups: A practical guide for applied research (3rd ed.). Thousand Oaks, CA: Sage. 
Lara, M., Akinbami, L., Flores, G., \& Morgenstern, H. (2006). Heterogeneity of childhood asthma among Hispanic children: Puerto Rican children bear a disproportionate burden. Pediatrics, 117(1), 43-53.doi:10.1542/peds.2004-1714

Lehrer, P. M., Isenberg, S., \& Hochron, S. M. (1993). Asthma and emotion: A review. Journal of Asthma, 30(1), 5-21.

Leikauf, G. (2002). Hazardous air pollutants and asthma. Asthma Occurrence, 110(4), 505-526.

Lenney, W. (1997). The burden of pediatric asthma. Pediatric Pulmonology, 24(S15), 1316. doi:10.1002/(SICI)1099-0496(199709)15+<13::AID-PPUL4>3.0.CO;2-S

Liamputtong, P. (2011) Focus group methodology: Principles and practice. Thousand Oaks, CA. Sage

Lim, A., Cranswick, N., \& South, M. (2010). Adverse events associated with the use of complementary and alternative medicine in children. Archives of Disease in Childhood, 96(3), 297-300. doi:10.1136/adc.2010.183152

Martinez-Cruzado, J. C., Toro-Labrador, G., \& Viera-Vera, J. (2005). Reconstructing the population history of Puerto Rico by means of mtDNA phylogeographic analysis. American Journal of Physical Anthropology, 128, 131-155.

Mason, M. (2010). Sample size and saturation in Ph.D. studies using qualitative interviews. Forum: Qualitative Social Research, 11(3). doi:10.17169/fqs11.3.1428

McGuire, T. G., Alegria, M., Cook, B. L., Wells, K. B., \& Zaslavsky, A. M. (2006). Implementing the Institute of Medicine definition of disparities: An application to 
mental health care. Health Services Research, 41(5), 1979-2005.

doi:10.1111/j.475-6773.2006.00583.x

McQuaid, E., Kopel, S., Klein, R., \& Fritz, G. (2003). Medication adherence in pediatric asthma: Reasoning, responsibility, and behavior. Journal of Pediatric.

Psychology, 28(5), 323-333. doi:10.1093/jpepsy/jsg022

McQuaid, E. L., Vasquez, J., Canino, G., Fritz, G. K., Ortega, A. N., Colon, A., ... Seifer, R. (2009). Beliefs and barriers to medication use in parents of Latino children with asthma. Pediatric Pulmonology, 44(9), 892-898. doi:10.1002/ppul.21074

McQuaid, E. L., Everhart, R. S., Seifer, R., Kopel, S. J., Mitchell, D. K., Klein, R. B., ... Canino, G. (2012). Medication adherence among Latino and non-Latino White children with asthma. Pediatrics, 129(6), e1404-1410. doi:10.1542/peds.20111391

Molfino, N., Nannini, L., Martelli, A., \& Slutzky, A. (1991). Respiratory arrest in near fatal asthma. New England Journal of Medicine, 324, 285-288. doi:10.1056/NEMJ1991011313240502

Mowrer, J. L., Tapp, H., Ludden, T., Kuhn, L., Yhenneko, T., Courtland, C., ... Dulin, M. (2015). Patients' and providers' perceptions of asthma and asthma care: A qualitative study. Journal of Asthma, 52(9), 949-956. doi: $10.3109 / 02770903.2015 .1010731$

National Institute of Health. (2013). National Heart, Lung and Blood Institute Expert Panel Report 3 (EPR3): Guidelines for the diagnosis and management of asthma. Retrieved from http://www.nhlbi.nih.gov/guidelines/asthma/asthgdln.htm 
Neff, N. (2014). Folk medicine in Hispanics in the southwestern United States Module VII. Retrieved May 21, 2015, from http://www.rice.edu Office of Disease Prevention and Health Promotion. (2018). Healthy People 2020 Respiratory Diseases. Retrieved from http://www.healthypeople.gov/2020/topicsobjectives/topic/respiratory-diseases?t

Pachter, L. M., Cloutier M. M., \& Bernstein B. A. (1995). Ethnomedical (folk) remedies for childhood asthma in a mainland Puerto Rican community. Archives of Pediatric \& Adolescent Medicine, 149(9), 982.

doi:10.1001/archpedi.1995.02170220048007

Patterson, T. L. (2013). The effect of caregivers' health literacy and disease knowledge on pediatric patients with asthma (Order No. 3560590). Available from Dissertations \& Theses @ Walden University. (1357120066). Retrieved from https://ezp.waldenulibrary.org/login?url=https://search-proquestcom.ezp.waldenulibrary.org/docview/1357120066?accountid=14872

Pelaez, S., Lamontagne, A., Collin, J., Gauthier, A., Grad, R., Blais, L., ... Ducharme F. (2015). Patients' perspective of barriers and facilitators to taking long-term controller medication for asthma: A novel taxonomy. BMC Pulmonary Medicine, 15(1), 1-11. doi:10.1186/s12890-015-0044-9

Reed, C. E. (2006). The natural history of asthma. Journal of Allergy and Clinical Immunology,118(3), 543-548. doi.10.1016/j.jaci.2006.06.020

Rossman, G. B., \& Rallis, S. F. (2003). Learning in the field: An introduction to qualitative research. Thousand Oaks, CA: Sage 
Shenton, A. K. (2004). Strategies for ensuring trustworthiness in qualitative research projects. Education for Information, 22(2), 63-75. doi.10.3233/EFI-2004-22201

Trochim, W. K. (2006) Qualitative validity. Retrieved from http://www.socialresearchmethods.net/kb/qualval.php

Torres, E., \& Sawyer, T. (2005). Curandero: A life in Mexican folk healing. Albuquerque, NM: University of New Mexico Press.

Ulin, P., Robinson, E., \& Tolley, E. (2005). Qualitative data analysis. In Qualitative methods in public health (pp. 146-147). San Francisco, CA: Jossey-Bass.

United States Department of Health and Human Services. (2013). Healthy People 2020: Asthma, topics and objectives. Retrieved from http://www.healthypeople.gov/2020/topicsobjectives2020/overview.aspx United States Department of Health and Human Services. (2014). Asthma Definition. Retrieved from https://www.nhlbi.nih.gov/health-topics/asthma United States Census Bureau. (2018). Definition of Hispanic/Latino. Retrieved from https://www.census.gov/topics/population/hispanic-origin/about.html

Valerio, M. A., Andreski, P. M., Schoeni. R. F., \& McGonagle, K. A. (2010). Examining the association between childhood asthma and parent and grandparent status: Implications for practice. Clinical Pediatrics, 49(6) 535-541. doi:10.1177/0009922809356465

Wernette, D. R., \& Nieves, L.A. (1992). Breathing polluted air. EPA Journal, 18, 16-17. Wood, P. R., Hidalgo, H. A., Prihoda, T. J., \& Kromer, M. E. (1993). Hispanic children with asthma: Morbidity. Pediatrics, 91(1), 62. 
World Health Organization. (2018). Medication adherence definition. Retrieved from http://apps.who.int/medicinedocs/en/d/Js4883e/8.1.1.html

Zayas, L. E., Wisniewski, A. M., Cadzow, R. B., \& Tumiel-Berhalter, L. M. (2011). Knowledge and use of ethnomedical treatments for asthma among Puerto Ricans in an urban community. Annals of Family Medicine, 9(1), 50-6 doi:10.1370/afm. 1200 
Appendix A: Interview Questionnaire (English)

Parents Perceptions about their Children's Asthma and Asthma Medications

Dear parents/caregivers: I would like to ask you about your personal perceptions about asthma disease and the medications prescribed for your child's asthma. There are no right or wrong answers. I am interested in your personal views, so please use your own words to answer the questions.

Please answer the following questions:

Parents age: ___ Ethnicity: ___ Place of birth: ___ Child age:

1. How did you and your family feel when you heard the diagnosis of asthma for your child?

2. In what ways does knowing your child needs asthma medication worry you?

3. Can you explain in your own words the asthma treatment that was prescribed for your child?

4. What was your feeling when you hear the word corticosteroid?

5. Have you ever worried about the long-term effects of your child's asthma medication including the use of corticosteroids?

6. If yes (to \#5), what kind of worry?

7. Have you ever stopped or decreased the asthma medication for any reason?

8. If the answer is yes, why did you stop? (Prompt - was it because of concern about the medication's side effects?)

9. Have you explored the use of herbal medicine for the treatment of your child's asthma?

10. If yes:

(a) which herbal medicines? 
(b) where did you get them?

(c) how did you know how to use them?

(d) in what ways were they effective or not effective?

(e) did your child have herbal medicines as well as an inhaler, or did you use the herbs instead of an inhaler? Please explain

11. What is your biggest worry about your child's asthma diagnosis?

12. What was the economic impact of the asthma diagnosis in your family?

13. Do you receive an asthma action plan for when your child suffers an asthma crisis?

14. If yes, could you please describe any occasion when you followed the plan?

15. Have you ever received education about asthma and asthma medications?

16. If yes (to \#15), who educated you and when?

17. If yes (to \#15), what kind of education did you receive? 
Appendix B: Interview Questionnaire (Spanish)

Percepción de los padres sobre la condición de asma en sus niños y la terapia de medicamentos.

Estimados padres/proveedores de cuidado:

Me gustaria preguntarles sobre su percepción personal sobre la enfermedad de asma y sobre los medicamentos prescritos para la condición de su hijo. No existe una respuesta correcta o incorrecta. Yo estoy solamente interesada en su visión personal, por favor utilize sus propias palabras para contestar las preguntas.

Por favor conteste las siguientes preguntas:

Edad de los padres: ___ Etnicidad: ___ Lugar de Nacimiento:

Edad del Niño :

1. ¿Como se sintieron usted y su familia cuando escuho el diágnostico de asma en su niño (a)?

2. ¿En que forma el conocer que su niño(a) necesita tomar medicamentos para el asma le preocupa a usted?

3. ¿Podria explicar en sus propias palabras el regimen de medicamentos para el asma que recibe su niño(a)?

4. ¿Cual se sintio cuando usted escucho la palabra corticosteroide por primera vez?

5. ¿Alguna vez se ha preocupado usted por los efectos a largo plazo de los medicamentos para el asma de su niño?

6. Si la contestación es afirmativa, ¿Qque tipo de preocupación? 
7. ¿Alguna vez a usted detenido o disminuido los medicamentos para el asma por alguna razón?

8. Si la contestación es afirmativa (lo detuvo debido a su preocupación por los efectos secundarios?

9. ¿Ha explorado el uso de hierbas medicinales para el tratamiento del asma de su $\operatorname{niño(a)?~}$

10. Si la contestación es afirmativa: $i$

(a) ¿Que tipo de hierba medicinal utilizó?

(b) ¿Donde la adquirió?

(c)¿Como aprendió a utilizarla?

(d) ¿En que medida fue efectiva o no fue efectiva?

(e) ¿Ha utilizado hierbas medicinales al mismo tiempo que el inhalador, o solo ha utilizado hierbas medicinales en vez del inhalador? Por favor explique?

11. ¿Cúal es su mayor temor relacionado con el diágnostico de asma de su niño(a)?

12. ¿Cúal ha sido el impacto económico del diágnostico de asma en usted y su familia?

13. ¿Usted ha recibido un plan de acción cuando su hijo(a) sufre una crisis de asma? 14.¿Si la contestación es afirmativa, podria usted describir alguna ocasión donde usted siguio el plan?

15. ¿A recibido alguna vez educación sobre asma y sobre los medicamentos para el asma?

16. Si la contestación es afirmativa: ¿Quién lo educó y cuando?

17. Si la contestación es afirmativa en la preguta 15, ¿Qque tipo de educación recibio? 
Appendix C: Study Promotion and Invitation to Participate (English)

\section{ATTENTION PARENTS / CAREGIVERS}

Do you have a child that have been diagnosed with Asthma for a year and is:

between the ages of 1 to 17 years old

from parents that born in Puerto Rico and

Utilized corticosteroids and bronchodilators, inhaled or oral as part of their asthma treatment?

If the answer is yes, you can participate in a study about the parents beliefs about their child asthma treatment

For more information please contact:

Luz Nieves

E-mail: luz.nieves@waldenu.edu 
Appendix D: Study Promotion and Invitation to Participate (Spanish)

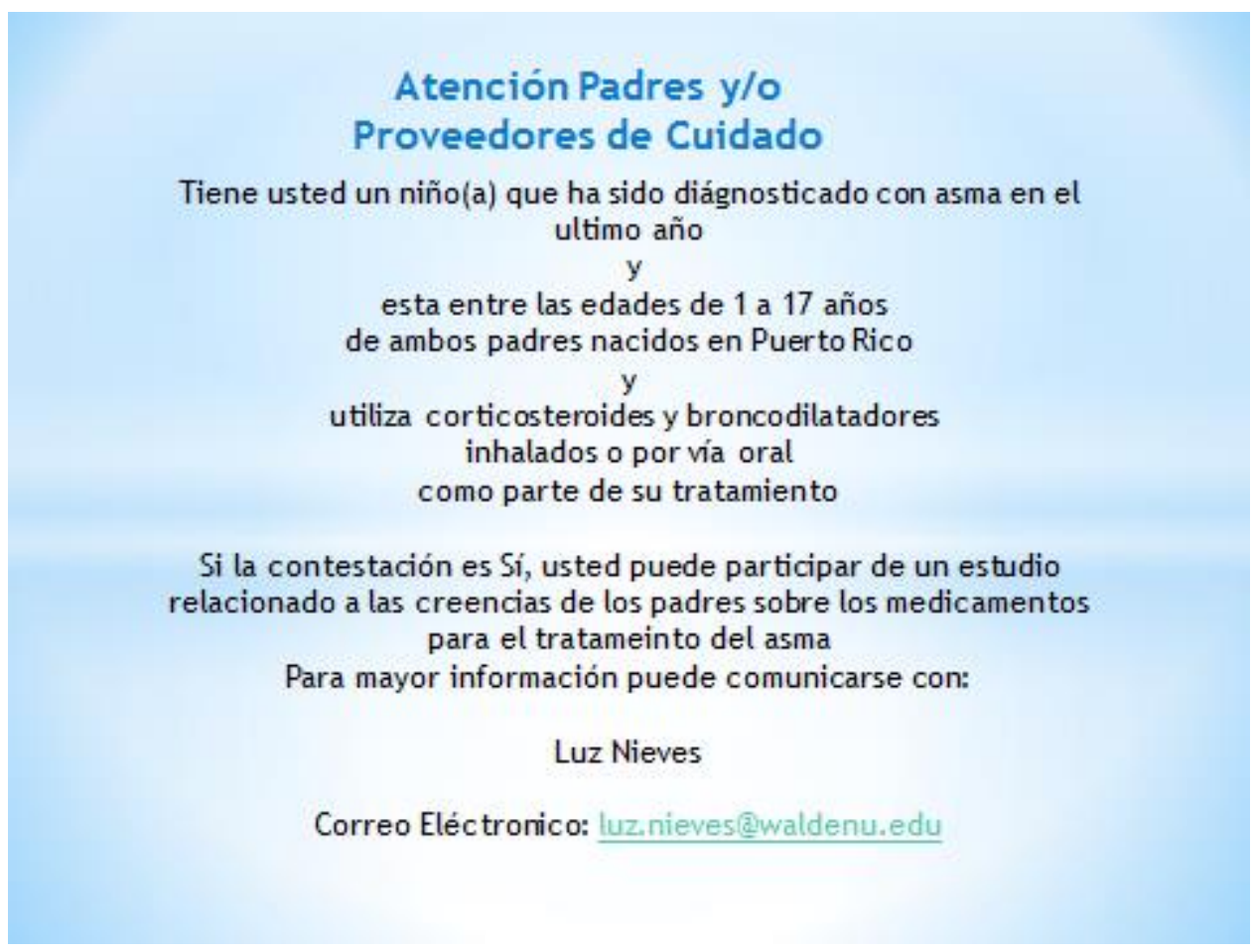


Appendix E: Parent/Caregivers’ Invitation Letter (English)

Dear parents/caregivers:

My name is Luz Nieves, and I am a student of the doctoral program at Walden University working on my doctoral dissertation study. The tittle of the dissertation is Asthma among Puerto Rican Children: Parents and Health Professionals’ Beliefs about Medication Noncompliance. This investigation is needed to explore how caregivers' beliefs affect asthma treatment compliance.

You have been invited to take part of this study by participating of an interview. For the interview the researcher will be utilizing a 17 questions questionnaire. This process will take around an hour to complete.

This is a voluntary study, and there are no correct or incorrect answers. The participants will receive a dust mite and allergy pillow encasing for their participation.

Consent to participate in the study needs to be signed before you start completing the questionnaire and can be found on the next page. If you have any questions about this process or would like more information, you can contact me at my university e-mail: $\underline{\text { luz.nieves@waldenu.edu }}$

Thank you for your cooperation!

Luz Nieves, RN, MPH 
Appendix F: Parent/Caregivers’ Invitation Letter (Spanish)

Estimados padres/proveedores de cuidado:

Mi nombre es Luz Nieves y soy estudiante del programa doctoral de la Universidad de Walden, y estoy trabajando en mi disertación doctoral. El título de mi disertación es:

Asma en la Niñez Puertorriqueña: Creencias de los Padres y los Profesionales de la Salud sobre sobre el Incumplimiento de Tratamiento. Esta investigación es necesaria para explorar como las creencias de los padres puede afectar la adherencia al tratamiento. Usted ha sido invitado a tomar parte del estudio por medio de completar una entrevista utilizando un cuestionario de 17 preguntas que solo le tomará alrededor de una hora en completar. Este es un estudio voluntario y no hay contestaciones correctas o incorrectas. Los participantes recibirán una cubierta de almohada hipoallergénica por su participación en el estudio. Antes de comenzar el estudio se necesita firmar una hoja de consentimiento. Si usted tiene alguna pregunta sobre este proceso o desea información adicional, puede contactarme a través de mi correo eléctronico de la Universidad de Walden a: luz.nieves@waldenu.edu ¡Gracias por su cooperación!

Luz Nieves, RN, MPH 


\section{Appendix G: Focus Group Questions}

1. Have you noticed a low adherence to asthma medication in children of Hispanic origin compared to children from other ethnic groups?

2. What do you think are the reasons for low adherence to asthma medications in children of Hispanic origin?

3. How often do you see the use of herbal remedies for the treatment of asthma in children?

4. What is your view of parents giving their children herbal remedies for asthma?

5. How do you deal with non-compliant parents regarding asthma treatment for their children?

6. What other challenges do you face when treating asthma in children of Hispanic origin?

7. Do you think that parental culture affects treatment adherence? If the answer is yes.

8. In which way the parents culture affects treatment adherence? 


\section{Appendix H: Permission for the Utilization of Dr. Glorisa Canino's Study Model}

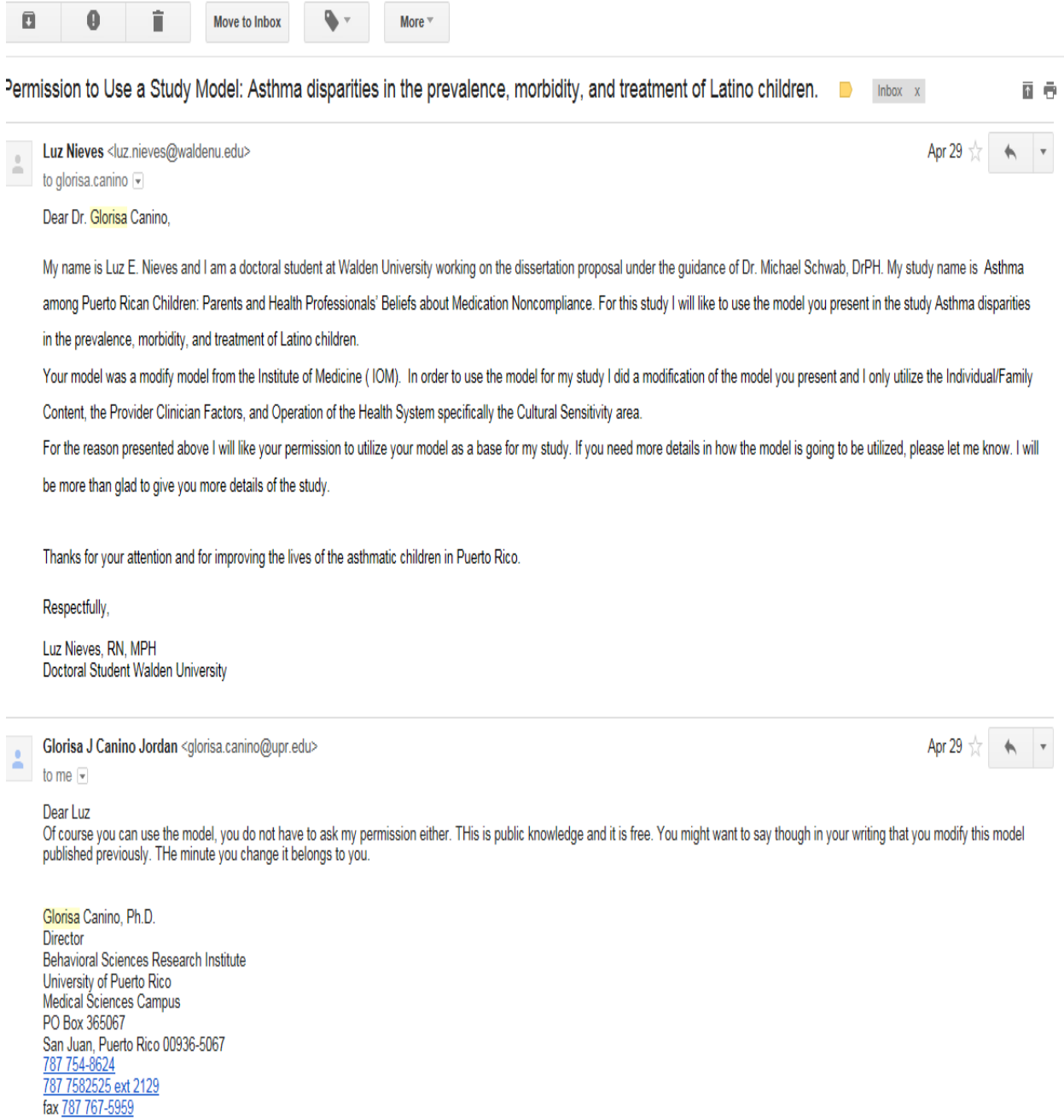


Appendix I: Focus Group Invitation Letter

Dear Health Care Provider:

My name is Luz Nieves, and I am a student of the doctoral program at Walden University working on my doctoral dissertation study. The tittle of the dissertation is Asthma among Puerto Rican Children: Parents and Health Professionals’ Beliefs about Medication Noncompliance.

This investigation is needed to explore how caregivers' and health care professional's beliefs affect asthma treatment compliance.

You have been invited to take part of this study by participating on a focus group. To guide the focus group activity the researcher will utilize eight questions relate to the study topic. This process will take around an hour to complete. This is a voluntary study, and there are no correct or incorrect answers.

Consent to participate in the study, needs to be signed before you start and can be found on the next page. If you have any questions about this process or would like more information, you can contact me at my university e-mail: luz.nieves@waldenu.edu

Thank you for your cooperation!

Luz Nieves, RN, MPH 